\title{
Simulation of circulating fluidized bed gasification for characteristic study of pakistani coal
}

\author{
Naveed Ramzan', Muhammad Athar ${ }^{2}$, Sharmina Begum ${ }^{3}$, Syed Waqas Ahmad ${ }^{4}$, Shahid Naveed ${ }^{5}$ \\ ${ }^{1}$ University of Engineering and Technology, Department of Chemical Engineering, G.T. Road, Lahore 54890, Pakistan \\ ${ }^{2}$ Project Development Directorate, DH Fertilizers Limited, 28-km Lahore Sheikhupura Road, Lahore, Pakistan \\ ${ }^{3}$ School of Engineering and Technology, Faculty of Sciences, Engineering and Health Central Queensland University, \\ Rockhampton, Qld 4702, Australia \\ ${ }^{4}$ University of Engineering \& Technology (Lahore) Faisalabad Campus, Department of Chemical \& Polymer Engineering, \\ Faisalabad, Pakistan \\ ${ }^{5}$ Pakistan Institute of Contemporary Sciences, Raiwind Lahore, Pakistan \\ "Corresponding author: e-mail: Syed.waqas.ahmad@gmail.com
}

\begin{abstract}
A process model for turbulent pressurized circulating fluidized-bed coal gasifier is created using ASPEN PLUS software. Both hydrodynamic and reaction kinetics parameter are taken into account, whose expressions for fluidized bed are adopted from the literature. Various reactor models available in ASPEN PLUS with calculator as External Block are nested to solve hydrodynamics and kinetics. Multiple operational parameters for a pilot-plant circulating fluidized-bed coal gasifier are used to demonstrate the effects on coal gasification characteristics. This paper presents detailed information regarding the simulation model, including robust analysis of the effect of stoichiometric ratio, steam to coal ratio, gasification temperature and gasification agent temperature. It is observed that, with the increase in the flow rate of air, the components hydrogen, carbon monoxide, carbon dioxide and methane reduce, which causes the Lower Heating Value (LHV) of synthesis gas (Syn. Gas) to decrease by about $29.3 \%$, while increment in the steam flow rate shows a minute increase in heating value of only $0.8 \%$. Stoichiometric ratio has a direct relationship to carbon conversion efficiency and carbon dioxide production. Increasing the steam to coal ratio boosts the production of hydrogen and carbon monoxide, and causes a drop in both carbon dioxide concentration and the conversion efficiency of carbon. High gasifying agent temperature is desired because of high concentration of $\mathrm{CO}$ and $\mathrm{H}_{2}$, increasing carbon conversion and LHV. A high gasifying agent temperature is the major factor that affects the coal gasification to enhance $\mathrm{H}_{2}$ and $\mathrm{CO}$ production rapidly along with other gasification characteristics.
\end{abstract}

Keywords: ASPEN PLUS, circulating fluidized bed, coal, gasification, simulation.

\section{INTRODUCTION}

Energy is the basic necessity of civilization and has a vital role in civilization social \& cost-effective development via improvement in quality and standard of living. The economic development status for any locality is related to the energy consumption pattern ${ }^{1}$. Increase in urbanization, human population and modernization has resulted in an ever increasing demand of energy ${ }^{2}$. The projected increase in global energy demand may be sharp over the coming years. The worldwide consumption of oil is 85 million barrels/day at present and may reach to 113 million barrels by $2030^{2}$.

Gasification is the process that converts solid feedstock into a combustible gas. This converts solid coal into gas fuel that can be cleaned easily and has advantages in comparison with direct combustion of coal that results in pollutants ${ }^{3-6}$. Fluidized bed gasifiers are advantageous over the other types of gasifiers due to higher throughput, improved heat and mass transfer from fuel, high heating value, reduced char and ash removal simplicity. The main types of fluidized bed gasifiers are bubbling and circulating, both have their advantages and disadvantages. It proves that circulating fluidized bed (CFB) gasifier better due to high resistance time and improved mass and heat transfer, which results in a high conversion ${ }^{7,8}$.

ASPEN PLUS is a powerful numerical computation and simulation tool with built-in numerical functions for optimization of various parameters. Some of the simulation studies using this tool are coal liquefaction, synthesis of methanol and gasification processes. Models of biomass gasification have been developed for bubbling and circulating fluidized beds, ${ }^{9}$. Solid feed with sand as bed material is subjected to fluidization through gasifying agents, i.e. steam and air which enter at the bottom of CFB gasifier. The Syn. Gas produced from this process passes through a cyclone separator for solid particles separation from the Syn. Gas.

The current study is aimed at developing a suitable simulation model for Circulating Fluidized Bed Gasifier using ASPEN PLUS to encompass both the kinetics and hydrodynamics. Since the model for simulation of fluidized bed is not available in ASPEN PLUS, therefore FORTRAN/ MS Excel code is used to develop a model.

\section{SIMULATION MODEL}

Both kinetic and hydrodynamic parameters are considered in the model development due to their influence in the fluidized bed gasification. The fluidized bed gasification is assumed to take place in four steps. These stages include coal decomposition, volatile combustion, char gasification and cleaning with recycle. 


\section{ASSUMPTIONS}

\section{General Assumptions}

The following assumptions have been considered for modeling of the process:

1. Steady state and isothermal process.

2. Devolatilization is an instantaneous process with $\mathrm{H}_{2}, \mathrm{CO}, \mathrm{CO}_{2}, \mathrm{CH}_{4}$ and $\mathrm{H}_{2} \mathrm{O}$ as the products.

3 . For the emulsion phase, the distribution of all gases is uniform.

4. Assuming the shrinking core model, particles are assumed to be spherical and of uniform size during the gasification process.

5. The carbon char composition includes ash.

6. Gasification of Char initiates in the bed and completes in freeboard. According to Lee et al. ${ }^{\mathbf{1 1}}$, combustion and gasification takes place in the main bed region and pyrolysis in the freeboard region.

\section{Hydrodynamic Assumptions}

For hydrodynamics simulation, following assumptions have been made:

1. Fluidized bed reactor has two sections: bed and freeboard.

2. For the bubbling regime, fluidization state is maintained in the bed.

3. With increase in height, the volumetric fraction of solids decreases.

4. With increase in height, volumetric flow of gas increases.

5. The mixing of solid particles containing ash, char and sand as bed material is considered to be entirely perfect.

6. Finite equal reactor elements with constant hydrodynamic parameters are assumed.

7. Uni-dimensional fluidized bed is assumed and any change in the conditions would occur in the axial direction only.

The fluidization process consists of two sections; both have different governing hydrodynamic equations which are mentioned in Table 1.

Table 1. Fluidization hydrodynamic equations
Table 2. Gasification reactions ${ }^{8,11}$

\begin{tabular}{|c|c|c|}
\hline Reaction & $\begin{array}{l}\text { Reaction } \\
\text { Type }\end{array}$ & $\begin{array}{l}\text { Reaction } \\
\text { Number }\end{array}$ \\
\hline $\begin{array}{l}\mathrm{C}+\alpha \mathrm{O}_{2} \rightarrow 2(1-\alpha) \mathrm{CO}+(2 \alpha-1) \\
\mathrm{CO}_{2}\end{array}$ & Combustion & $\mathrm{R}-1$ \\
\hline $\mathrm{C}+\mathrm{H}_{2} \mathrm{O} \rightarrow \mathrm{CO}+\mathrm{H}_{2}$ & \multirow{4}{*}{ Gasification } & R-2 \\
\hline $\mathrm{CO}+\mathrm{H}_{2} \mathrm{O} \rightarrow \mathrm{CO}_{2}+\mathrm{H}_{2}$ & & R-3 \\
\hline $\mathrm{C}+2 \mathrm{H}_{2} \mathrm{O} \rightarrow \mathrm{CO}_{2}+2 \mathrm{H}_{2}$ & & R-4 \\
\hline $\begin{array}{l}\mathrm{C}+\mathrm{HH}_{2} \mathrm{O} \rightarrow(2-\beta) \mathrm{CO}+(\beta-1) \\
\mathrm{CO}_{2}+\beta \mathrm{H}_{2}\end{array}$ & & R-5 \\
\hline
\end{tabular}

Table 3. Reaction kinetic parameters ${ }^{11}$

\begin{tabular}{|l|c|c|}
\hline Parameter/ Reaction Type & Combustion & Gasification \\
\hline E/R [K] & 1,166 & 19,544 \\
\hline k [1/s.atm] & 0.046 & 6474.7 \\
\hline
\end{tabular}

\section{Gasification Kinetics}

Gasification process consists of gasification and combustion reactions which are presented in Table 2. The values of $\alpha$ and $\beta$ are $0.9^{9}$ and $1.4^{11}$ respectively determined the kinetics experimentally for bed and freeboard regions. Some kinetic factors used in modeling are available in Table 3.

\section{ASPEN PLUS Model Description}

Numerous ASPEN PLUS blocks have been integrated to simulate the circulating fluidized bed gasification process. The description of the ASPEN PLUS blocks is presented in Table 4. Figure 1 and Figure 2 (a, b) depict the CFB gasifier schematics, model for CFB gasification and the calculation sequence adopted. The RYIELD model in ASPEN PLUS is used for the decomposition of the feed. Coal is decomposed into its constituents by specifying the yield using the coal ultimate analysis data presented in Table 5.

For volatile combustion, we use ASPEN PLUS model RGIBBS. Here Gibbs equilibrium is assumed for volatile reactions. Before the RGIBBS reactor, we use SEPARATOR model for separation of the components for the volatile reactions to occur. The RCSTR model in ASPEN PLUS is used for gasification of char with use of reaction kinetics described by Lee et al. ${ }^{11}$, using CALCULATOR

\begin{tabular}{lll}
\hline Hydrodynamic Parameters & Section & $\begin{array}{l}\text { Parameter } \\
\text { Number }\end{array}$ \\
\hline$u_{m f}=\frac{33.7 \mu}{\rho_{g} d_{p}}\left(\sqrt{1+3.59 \times 10^{-5} A r}-1\right)$ & $\mathrm{H}-1$ \\
$A r=\frac{d_{p}^{3} \rho_{g}\left(\rho_{s}-\rho_{g}\right) g}{\mu^{2}}$ & $\mathrm{H}-2$ \\
$B=1.0+\frac{10.978\left(u-u_{m f}\right)^{0.738} \rho_{s}^{0.376} d_{p}^{1.006}}{u_{m f}^{0.937} \rho_{g}^{0.126}}$ & $\mathrm{H}-3$ \\
$\varepsilon_{b}=1-\frac{1}{B}$ & $\mathrm{H}-4$ \\
$\varepsilon_{f}=\varepsilon_{b}+\left(1-\varepsilon_{b}\right) \varepsilon_{m f}$ & $\mathrm{H}-5$ \\
\hline $1-\varepsilon_{f b}=\left(1-\varepsilon_{f}\right) \exp (-a z)$ & $\mathrm{H}-6$ \\
$a=1.6 / u$ & Freeboard & $\mathrm{H}-7$ \\
\hline
\end{tabular}




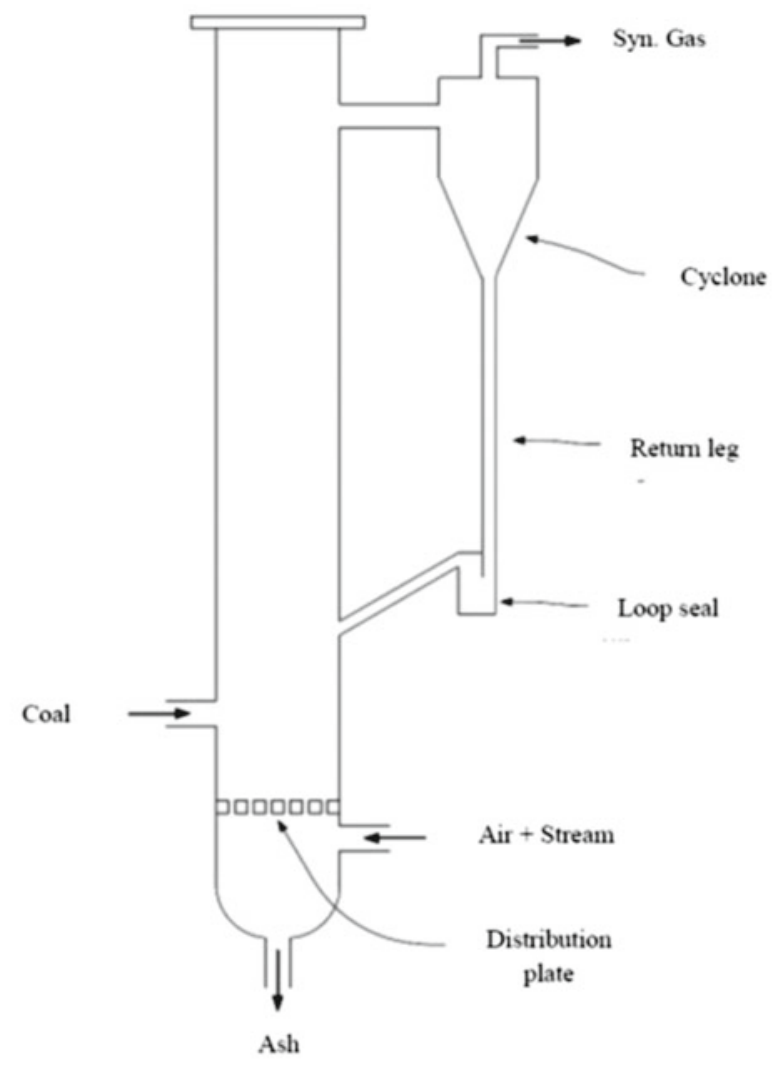

Figure 1. Schematic of Circulating Fluidized Bed Gasifier

block with a code. The reactor is divided into bed and freeboard regions using hydrodynamic parameters where each region is represented by one RCSTR. External CALCULATOR block divides each CSTR into equal volume CSTR reactors in series. Kinetics and hydrodynamic parameters e.g. superficial gas velocity, voidage, partial pressure of oxygen and steam remain unchanged in this little division of reactors.

\section{Model Validation}

For simulation results validation, experimental data of Bituminous coal in a pressurized CFB gasification pilot plant reactor was used ${ }^{12}$. Coal and bed material specifications and reactor configuration are presented in Tables 6 and 7 respectively. The model results are found to be in good agreement to that of the experimental results. The numerous coal fields of Pakistan, i.e. Thar, Sonda and Jhimpir are studied based on the same model and operating conditions. Data of these fields is available in Table 8. Pakistan coal fields results show similar behavior to that of model developed earlier.

\section{RESULTS AND DISCUSSION}

The results for stoichiometric ratio $(\Phi)$, steam to coal ratio (FS/FC) and preheated temperature of the gasifying agent $\left(\mathrm{T}_{\mathrm{ga}}\right)$ obtained from ASPEN PLUS model are generated and compared with the published experimental results ${ }^{12}$. These operational factors are investigated for different parameters that include gas composition, LHV, carbon conversion efficiency, cold gas efficiency and dry gas yield. In gas composition, five gases (i.e. Hydrogen, Carbon Monoxide, Carbon Dioxide, Methane, and Nitrogen) were considered to study gas production. However, this research work also deals with the influence of gasification temperature $(\mathrm{T})$ on the above mentioned parameters. Stoichiometric Ratio is defined as the ratio of inlet air to the air required for stoichiometric combustion. It is a measure of overall air to fuel ratio in a combustion system. Other definitions are given in Table 9 .

\section{Effect of Stoichiometric Ratio}

Experimental and Simulation results against seven stoichiometric ratios for gas composition, carbon conversion efficiency, gas yield, cold gas efficiency and LHV for a variation of $0.29-0.39$ are shown in Figure $3(\mathrm{a}-\mathrm{f})$. For Pakistan coal fields, the results of same parameters are shown in Figure 4 (a-f).

Two conflicting effects are observed on the gasification process for higher stoichiometric ratio. Gasification is favored by excess amount of air due to elevated temperature; on the other hand, it produces more carbon dioxide. However, the total amount of both carbon dioxide and carbon monoxide decreases with the excessive amount of air while the inert gas, i.e. $\mathrm{N}_{2}$ volume increases in the Syn. Gas for the simulation case. For Pakistan coal fields, the results for Syn. Gas main components i.e. $\mathrm{H}_{2}$ and $\mathrm{CO}$ are the maximum for coal from Jhimpir field with the minimum amount of $\mathrm{CO}_{2}$ that is desirable for Syn. Gas.

The carbon conversion efficiency increases in simulation model as well as in experimental results, however, for experimental case it increases rapidly up to $\Phi=0.35$ after which it becomes slow. While for simulation case the rate of efficiency increase remains constant for the whole variation of $\Phi$. For Pakistan coal fields, the rate of carbon conversion efficiency increase is the highest for Thar and the lowest for Jhimpir coal while the highest efficiency value is also for Thar coal. The dry gas yield increases with the enhanced flow rate of air for both simulation and experimental work and are in good agreement for a stoichiometric ratio above 0.35 . The dry gas yield from Jhimpir coal is the highest for elevated $\Phi$, with the lowest rate of increase in dry gas yield.

The trend for experimental results for cold gas efficiency is increasing higher stoichiometric ratios and the rate of increase becomes very slow above $\Phi=0.35$. But for simulation results a decrease in cold gas efficiency is observed due to less heating value. The best relation between experimental and simulation results is observed for high value of $\Phi$. For Pakistan coal fields, cold gas efficiency decreases for all fields with the highest rate of decrease for Thar field. The LHV for both simulation and experimental data shows decline with an increase in amount of air. For simulation case, this decline is smooth while for experimental results a continuous rise is observed up to $\Phi=0.34$ after which it starts to decline which is because of reduction of $\mathrm{H}_{2} \& \mathrm{CO}$ amounts in Syn. Gas. The LHV for all Pakistan coal fields show a decreasings trend with excess amount of air. For Thar coal field, the lowest LHV value is observed for any flow rate of air while the rate of LHV decrease is the maximum for coal from Jhimpir field with excess amount of air.

\section{Effect of Steam to Coal Ratio}

Experimental and simulation data against five values of FS/FC for gas composition, carbon conversion efficiency, gas yield, cold gas efficiency and LHV for a variation 
(a)

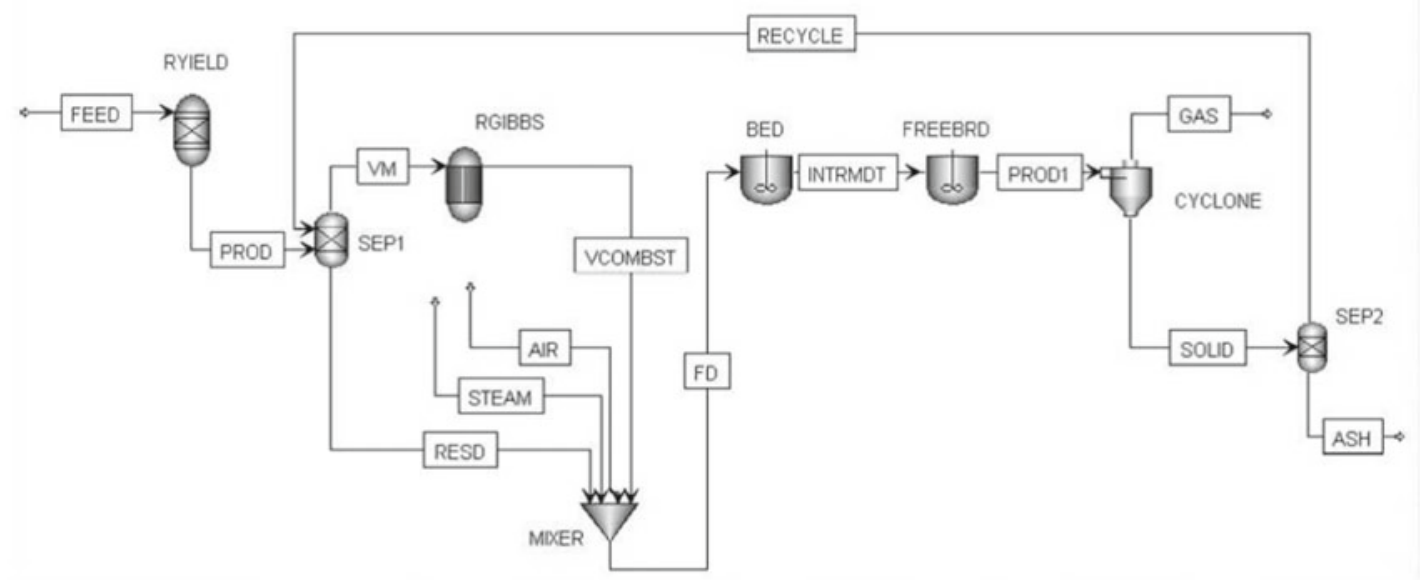

(b)

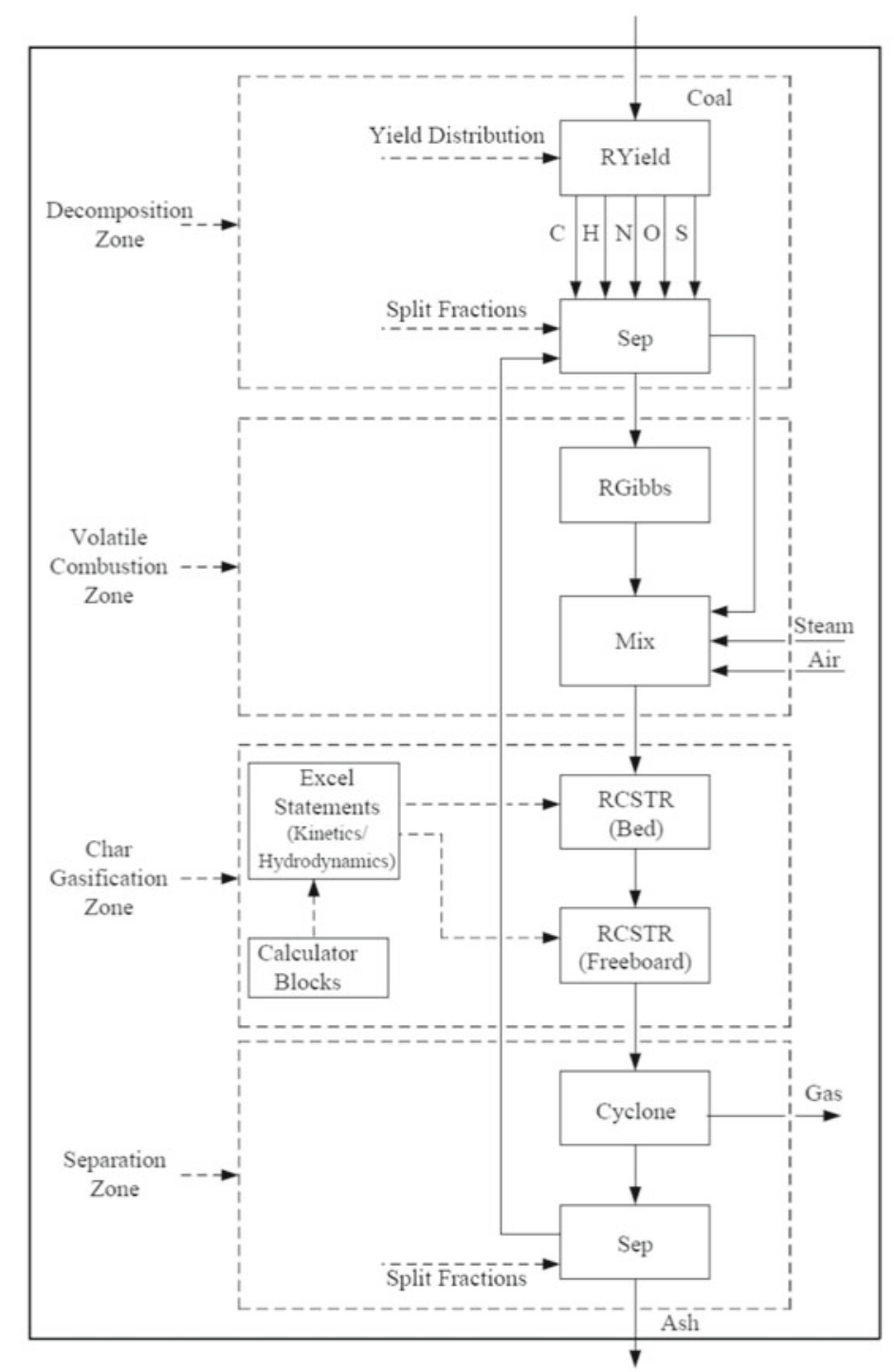

Figure 2. (a)ASPEN PLUS Simulation Model for Circulating Fluidized Bed Gasifier (b) ASPEN PLUS Calculation Sequence

of $0.32-0.52$ is presented in Figure 5 (a-f). For Pakistan coal fields, the results of same parameters are available in Figure $6(\mathrm{a}-\mathrm{f})$.

The results show that the steam/coal ratio affects the gas composition for experimental case significantly while for simulation the effect is little. The CO concentration exhibits a trend that is slowly decreasing when the FS/FC is increased in both cases; same is the case for $\mathrm{CO}_{2}$. The $\mathrm{H}_{2}$ concentration has an increasing trend while variation in $\mathrm{CH}_{4}$ concentration is very small. For Pakistan coal fields, same trends are observed for increasing steam flow rate. Jhimpir coal field produces high amount of desired components in gas than the coal from other two fields but the rate of desired components increase is the least for the Jhimpir coal. The carbon-steam reaction is highly temperature sensitive, as a little steam amount results in carbon conversion efficiency to increase slightly which drops by additional rise in steam amount in experimental case. The trend for Simulation case decreases gradually; 
Table 4. ASPEN PLUS blocks used in simulation

\begin{tabular}{|l|c|c|}
\hline $\begin{array}{l}\text { ASPEN } \\
\text { PLUS ID }\end{array}$ & Block ID(s) & Description \\
\hline RYield & RYIELD & $\begin{array}{c}\text { Models reactor with specified yield. } \\
\text { It is helpful when reaction } \\
\text { stoichiometry and kinetics are } \\
\text { unknown }\end{array}$ \\
\hline RGibbs & RGIBBS & $\begin{array}{c}\text { Models chemical and phase } \\
\text { equilibrium by Gibbs energy } \\
\text { minimization and useful when } \\
\text { reaction stoichiometry is unknown }\end{array}$ \\
\hline RCSTR & $\begin{array}{c}\text { Medels continuous stirred tank } \\
\text { reactor and can handle any phase } \\
\text { beased on known stoichiometry and } \\
\text { kinetics }\end{array}$ \\
\hline Cyclone & CYCLONE & $\begin{array}{r}\text { Separates solids from gas using gas } \\
\text { vortex in a cyclone }\end{array}$ \\
\hline Mixer & MIXER & $\begin{array}{c}\text { Combines multiple streams into one } \\
\text { stream }\end{array}$ \\
\hline
\end{tabular}

Table 5. Coal Characteristics ${ }^{12}$

\begin{tabular}{|l|c|}
\hline Proximate Analysis [wt \%] & 3.01 \\
Moisture & 27.53 \\
VM & 40.16 \\
FC & 29.3 \\
Ash & \\
\hline Ultimate Analysis [wt \%] & 54.8 \\
C & 3.54 \\
H & 7.47 \\
O & 0.88 \\
N & 1.00 \\
S & 7.5 \\
\hline Flow Rate $[\mathrm{kg} / \mathrm{hr}]$ & \\
\hline
\end{tabular}

Table 6. Material of bed \& size of particle distribution ${ }^{\mathbf{1 2}}$

\begin{tabular}{|c|c|c|c|}
\hline $\begin{array}{c}\text { Size of Particle } \\
{[\mathrm{mm}]}\end{array}$ & $\begin{array}{c}\text { Coal } \\
{[\text { Mass \%] }}\end{array}$ & $\begin{array}{c}\text { Size of Particle } \\
{[\mathrm{mm}]}\end{array}$ & $\begin{array}{c}\text { Material of Bed } \\
{[\text { Mass \%] }}\end{array}$ \\
\hline $0-0.1$ & 6.59 & $0-0.2$ & 6.49 \\
\hline $0.1-0.3$ & 22.1 & $0.2-0.4$ & 13.9 \\
\hline $0.3-0.5$ & 27.7 & $0.4-0.6$ & 23.6 \\
\hline $0.5-0.7$ & 19.5 & $0.6-0.8$ & 26.1 \\
\hline $0.7-0.9$ & 12.5 & $0.8-1.0$ & 21.6 \\
\hline$>0.9$ & 11.6 & $>1.0$ & 8.30 \\
\hline $\mathrm{d}_{\mathrm{p}}[\mathrm{mm}]$ & 0.5 & $\mathrm{~d}_{\mathrm{p}}[\mathrm{mm}]$ & 0.8 \\
\hline
\end{tabular}

Table 7. Experimental setup \& parameters for simulation ${ }^{11}$

\begin{tabular}{|l|c|}
\hline Fluidized Bed Reactor & $700-950$ \\
Temperature $\left[{ }^{\circ} \mathrm{C}\right]$ & 0.3 \\
Pressure $[\mathrm{MPa}]$ & 70 \\
Bed diameter [mm] & 1200 \\
Bed height $[\mathrm{mm}]$ & 60 \\
Diameter of Freeboard [mm] & 5400 \\
Height of Freeboard [mm] & 350 \\
\hline Air & $13.3-17.9$ \\
Temperature $\left[{ }^{\circ} \mathrm{C}\right]$ & 200 \\
Flow rate $\left[\mathrm{Nm}^{3} / \mathrm{hr}\right]$ & $2.4-3.9$ \\
\hline Steam & \\
Temperature $\left[{ }^{\circ} \mathrm{C}\right]$ & Flow rate $[\mathrm{kg} / \mathrm{hr}]$
\end{tabular}

Table 8. Proximate and ultimate analysis of pakistan coals ${ }^{\mathbf{1 3}}$

\begin{tabular}{|l|c|c|c|}
\hline & \multicolumn{1}{|l|}{ THAR } & SONDA & JHIMPIR \\
\hline Proximate & & & \\
Analysis [wt \%] & & & \\
Moisture & 42.55 & 35.30 & 31.60 \\
VM & 13.40 & 17.73 & 16.52 \\
FC & 38.61 & 41.2 & 41.11 \\
Ash & 5.44 & 5.77 & 10.77 \\
\hline Ultimate & & & \\
Analysis [wt \%] & & & \\
C & 60.24 & 61.43 & 60.2 \\
H & 6.68 & 6.9 & 6.82 \\
O & 25.75 & 21.26 & 18.24 \\
N & 0.34 & 0.31 & 0.32 \\
S & 1.55 & 4.33 & 3.65 \\
\hline
\end{tabular}

same trend for carbon conversion efficiency is observed for Pakistan coal fields.

The dry gas yield increases for low steam flow but declines for more increase in steam amount for experimental case while for simulation case no significant change is observed. It is because of the combustible components concentration increases by steam supplementation, that favors the dry gas yield, but after a certain amount of steam flow rate, it is observed that the reduction in combustible components which results in a decrease of the dry gas yield ${ }^{12}$. The overall trend of dry gas yield is increasing for all fields but the rate of change is very small by addition of steam. Jhimpir coal field produces about $8.5 \%$ more gas than the Thar field for same amount of coal.

For cold gas efficiency, the experimental results show growth initially and then decline with the same reason described earlier for yield. Simulation results have the slightly increasing trend but this rate of growth is too

Table 9. Definitions of parameters

\section{Definition}

$\eta c=\left(1-\frac{\text { Total rate of carbon in the outlet stream }}{\text { Total rate of carbon in the feed stream }}\right) \times 100 \%$

$$
\eta=\frac{H_{g} \times Y}{H_{C}}
$$

$$
L H V=\left(\frac{107.98 \times H_{2} \%+126.36 \times C O \%+358.18 \times \mathrm{CH}_{4}}{1000}\right)
$$

$$
Y=\frac{Q_{a} \times 79 \%}{W_{c} \times N_{2} \%}
$$


a)

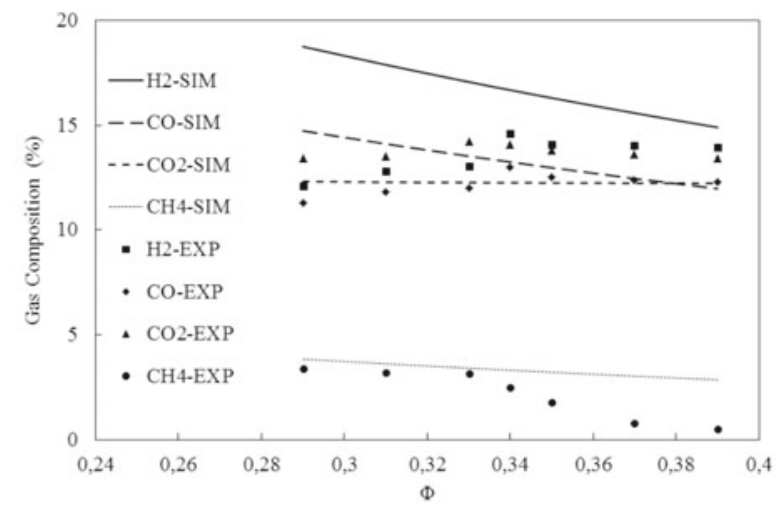

c)
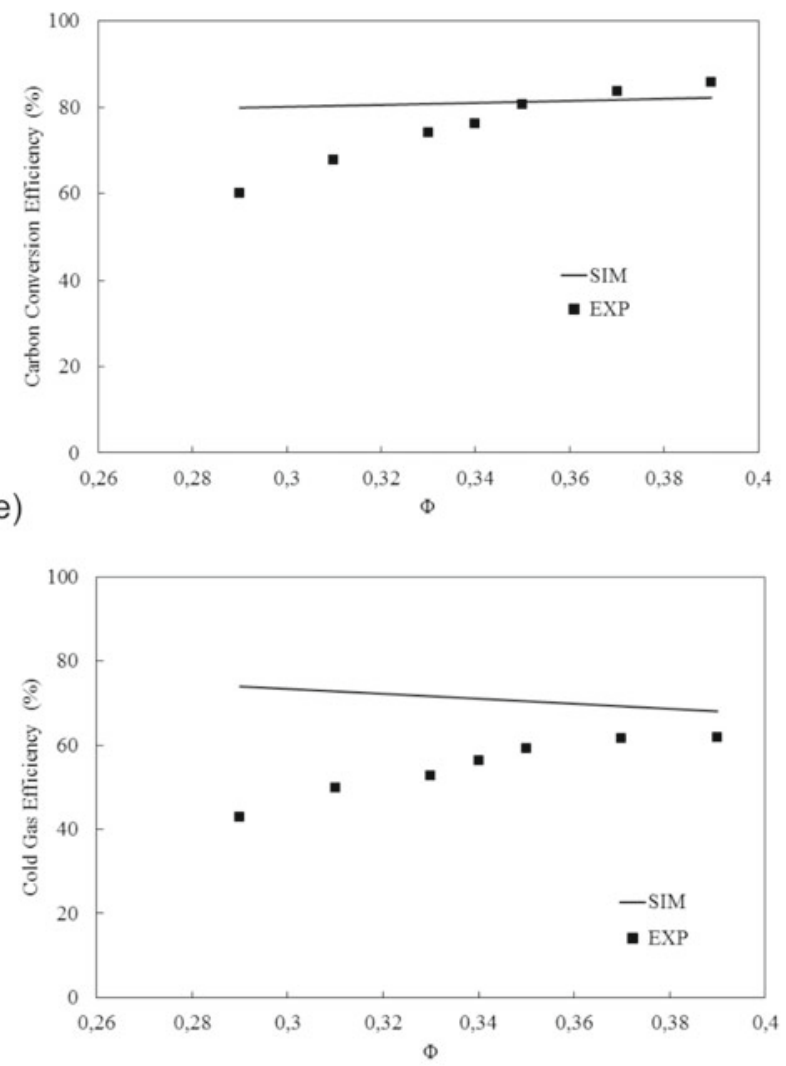

b)

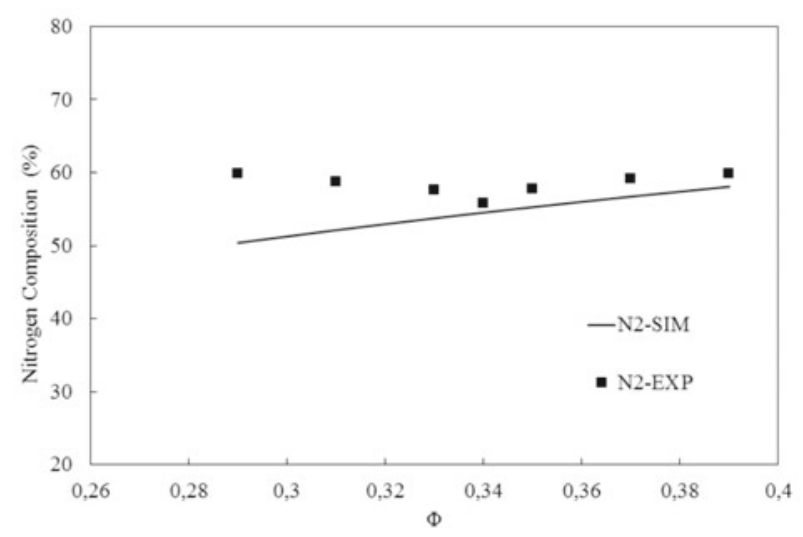

d)
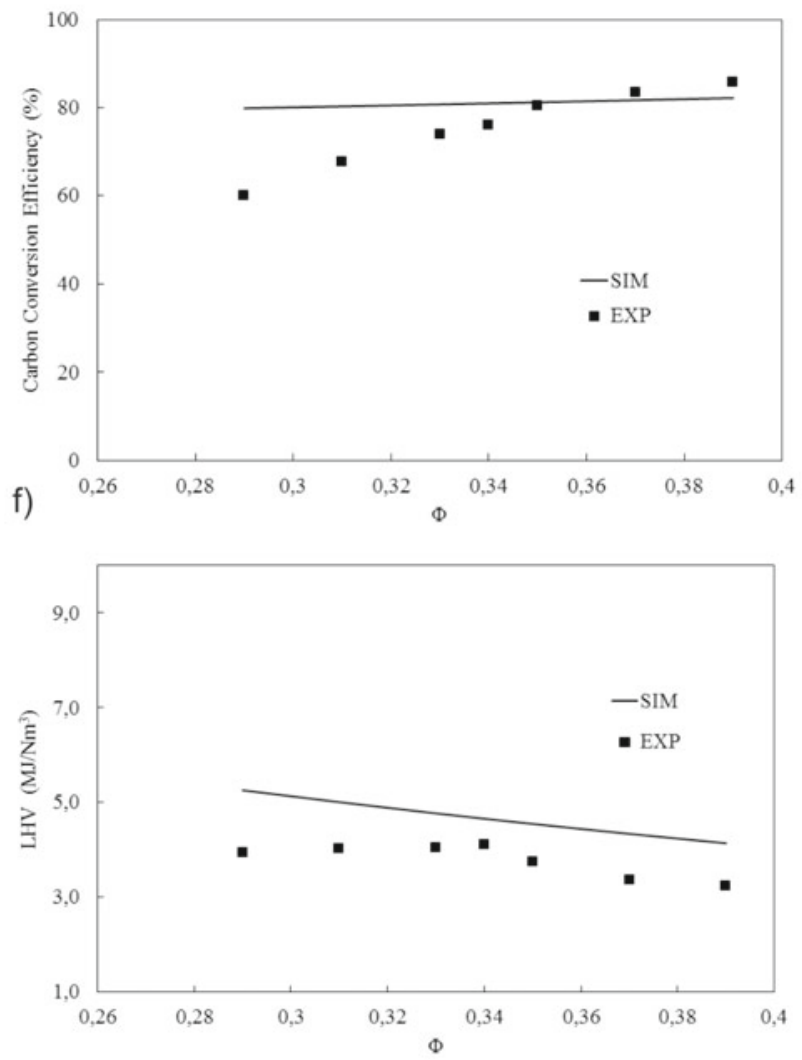

Figure 3. Effect of Stoichiometric Ratio on Gasification Parameters (Simulation vs. Experimental), Coal Feed Rate = 7.5 kg/h, $\mathrm{T}_{\mathrm{ga}}=700^{\circ} \mathrm{C}, \mathrm{FS} / \mathrm{FC}=0.38$, (a) Gas Composition (except Nitrogen), (b) Nitrogen Composition, (c) Carbon Conversion Efficiency, (d) Dry Gas Yield, (e) Cold Gas Efficiency, (f) Gas LHV

slow. As the heating value for coal from Jhimpir field has the highest value among the three, so same is the case for its cold gas efficiency. The gas LHV observes an increase followed by a decrease with maximum LHV obtained for $\mathrm{FS} / \mathrm{FC}=0.45$ in experimental case while for simulation the trend remains increasing throughout. As $\mathrm{H}_{2}$ concentration increases, Syn. Gas LHV observes increasing trend. For Pakistan coal fields, the rate of LHV increase is small for all coal fields but for Jhimpir, its value is the minimum.

\section{Effect of Gasification Agent Temperature}

Experimental and simulation results data versus numerous gasification agent temperatures $\left(\mathrm{T}_{\mathrm{ga}}\right)$ for gas composition, carbon conversion efficiency, gas yield, cold gas efficiency and LHV for a variation of $400-700^{\circ} \mathrm{C}$ are presented in Figure 7 (a-f). For Pakistan coal fields, same parameters results are available in Figure $8(a-f)$.
When gasification agent temperature is increased, the augmentation in $\mathrm{H}_{2}$ and $\mathrm{CO}$ concentrations is significant for experimental case; similarly slow growing trend of concentration can also be seen for simulation case. Same trends to that of simulation case are observed for Pakistani coal fields with the highest values of main components of Syn. Gas is observed for Jhimpir which has the lowest rate of increase for higher value of gasification agent temperature. With an increase in gasification agent temperature, the carbon conversion efficiency has slight declining trend for experimental case and increasing for simulation case. However, they are in better agreement with each other. For Pakistan coal fields, the maximum carbon conversion is achieved from Thar coal. The rate of increase in carbon conversion efficiency for Jhimpir field is slightly higher than that of Thar coal field.

For experimental case, the dry gas yield shows a decreasing trend while for simulation case results remain 
a)

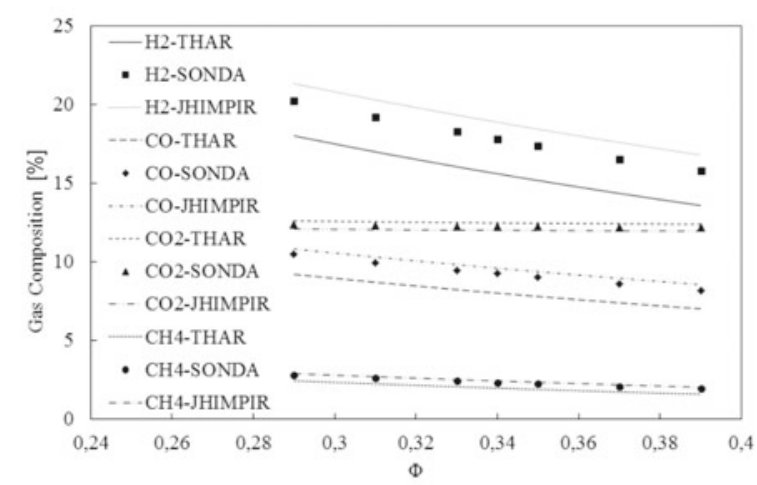

c)

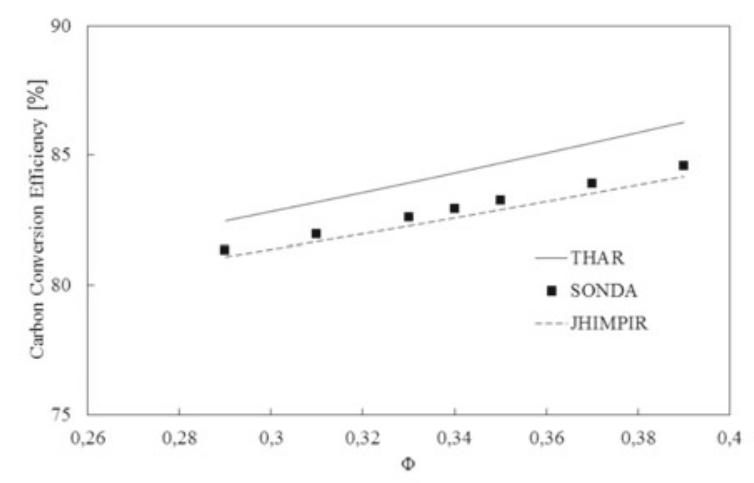

e)

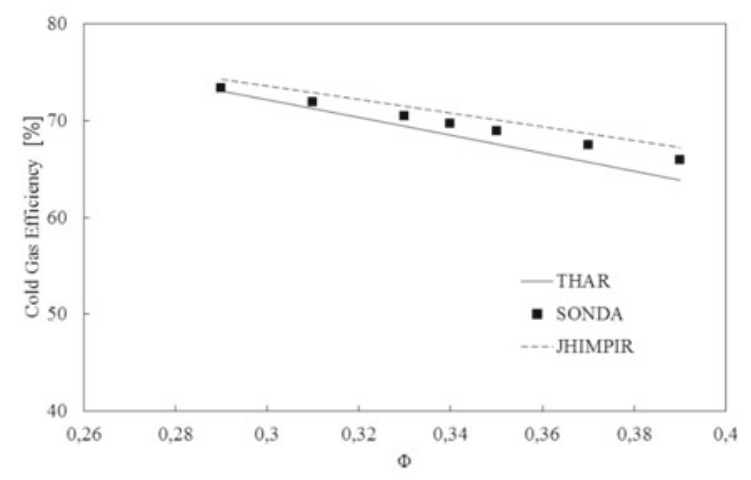

b)

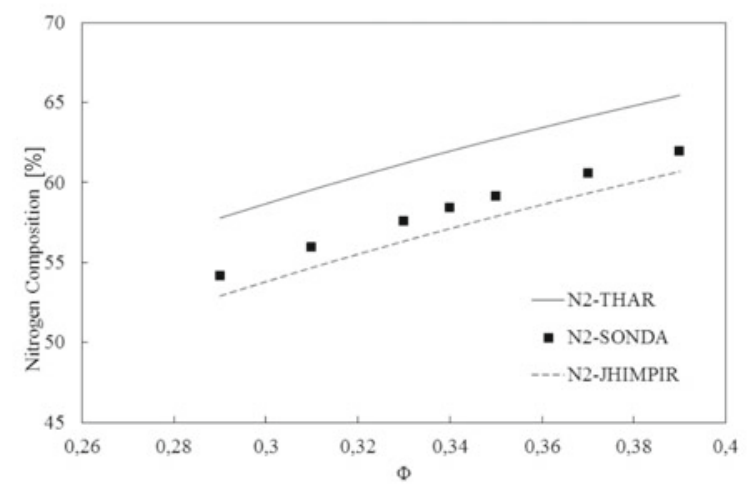

d)

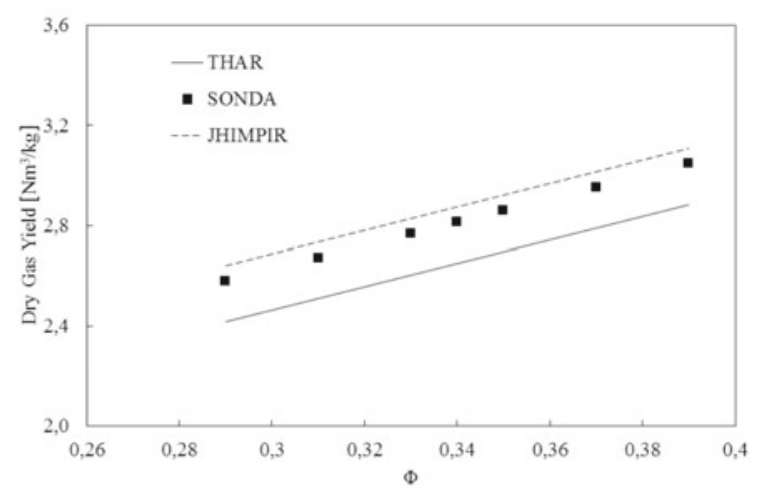

f)

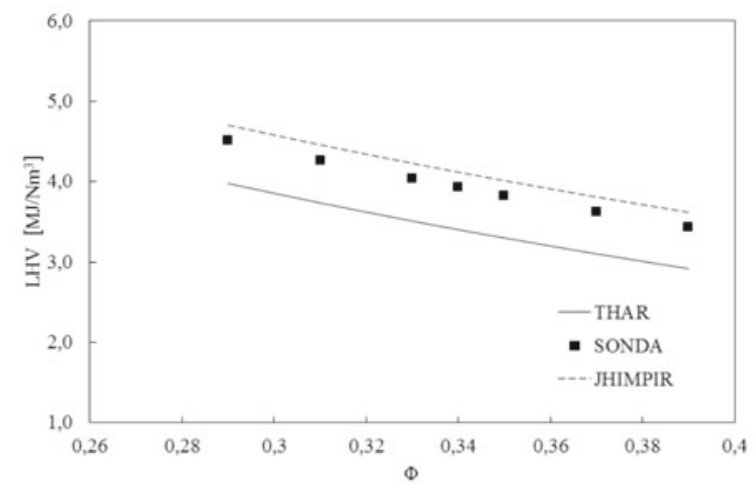

Figure 4. Effect of Stoichiometric Ratio on Gasification Parameters (Pakistan Coal Fields), Coal Feed Rate = 7.5 kg/h, $\mathrm{T}_{\mathrm{ga}}=700^{\circ} \mathrm{C}, \mathrm{FS} / \mathrm{FC}=0.38$, (a) Gas Composition (except Nitrogen), (b) Nitrogen Composition, (c) Carbon Conversion Efficiency, (d) Dry Gas Yield, (e) Cold Gas Efficiency, (f) Gas LHV

almost unchanged for increased values of gasification agent temperature. Chemical kinetics controls the rate of gasification i.e. temperature and partial pressure of reaction. The kinetics is affected by mixing and remains unchanged for the constant value of gasification temperature. No noticeable changes are observed in the dry gas yield and carbon conversion efficiency for elevated gasification agent temperature. Among Pakistan coal fields, the maximum yield is obtained from Jhimpir coal field while the other operating conditions remain same.

The experimental results show an increasing trend of cold gas efficiency which becomes slow for higher values of gasification agent temperature while for simulation case cold gas efficiency follows the same behavior in all respects. Here gasification temperature is assumed to be same for all values of gasification agent temperature. For Pakistan coal fields, the efficiency is higher for Jhimpir and rate of increase for increasing gasification agent temperature is higher for Thar. The trend of LHV for both simulation and experimental cases is on the increasing side which is slow for simulation case throughout. In the CFB coal gasification process; both exothermic and endothermic reactions take place at the same time. For a high-temperature of gasifying agent, the fraction of exo/endothermic reactions varies, which results in the higher LHV of Syn. Gas. The LHV for all Pakistan coal fields increases very slowly for higher gasification agent temperature. The slowest rate of increase is for Jhimpir coal and for same conditions a low heating value is observed from Thar coal.

\section{Effect of Gasification Temperature}

The effect of gasification temperature for simulation results for gas composition, carbon conversion efficiency, gas yield, cold gas efficiency and LHV is presented in Figure 9 (a-f). For Pakistan coal fields, same parameters results are available in Figure 10 (a-f). 
a)

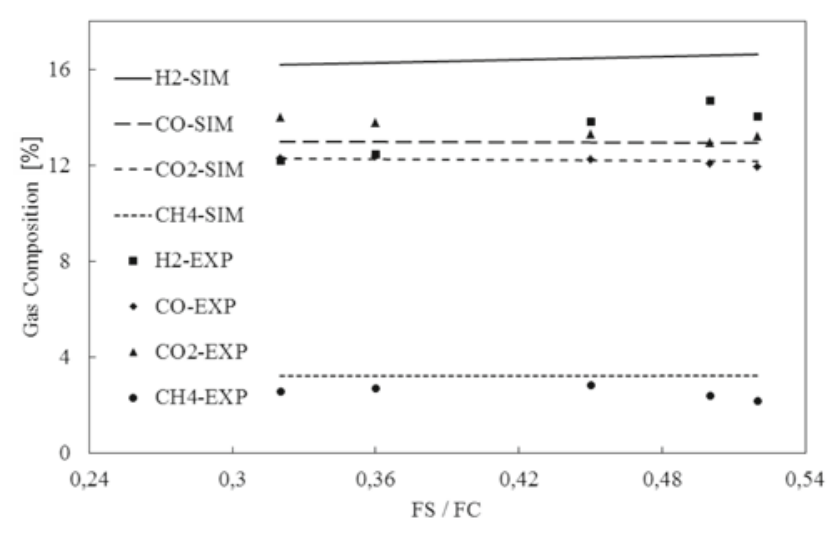

c)

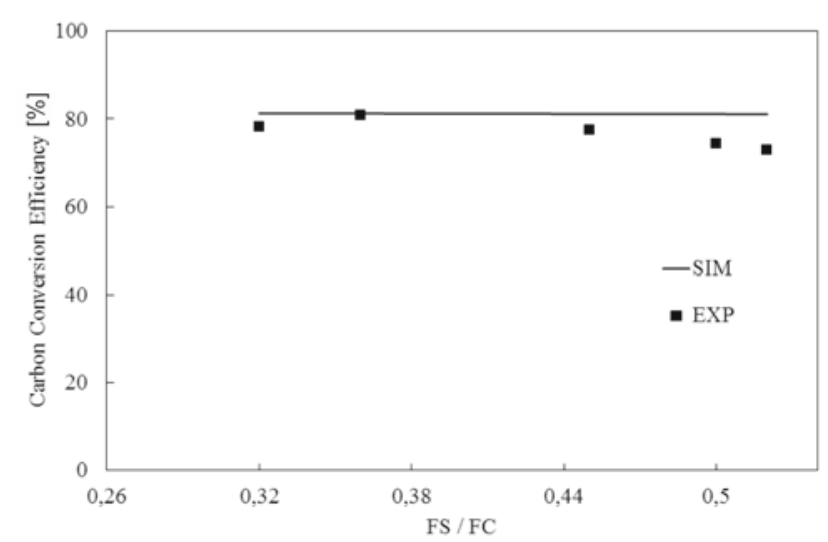

e)

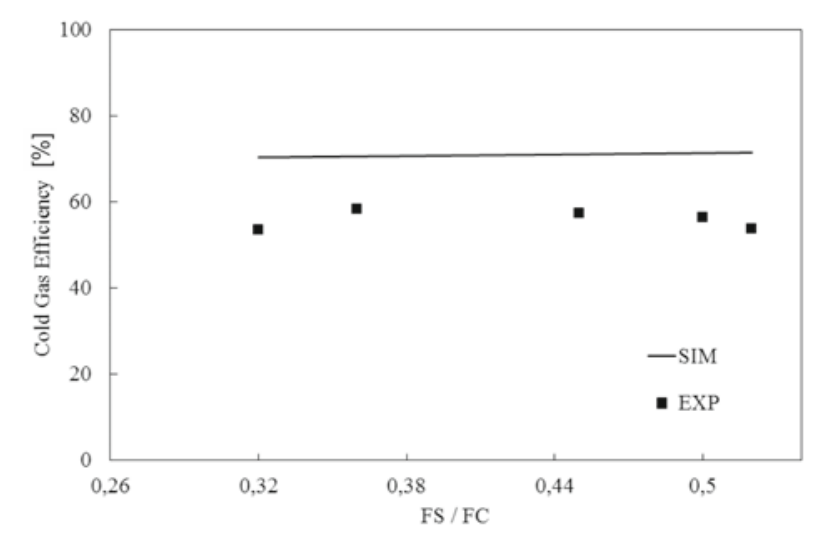

b)

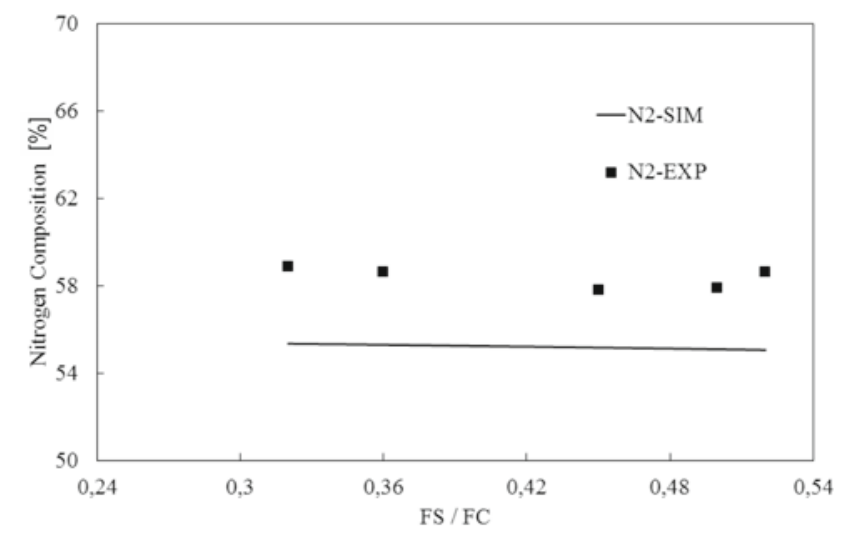

d)

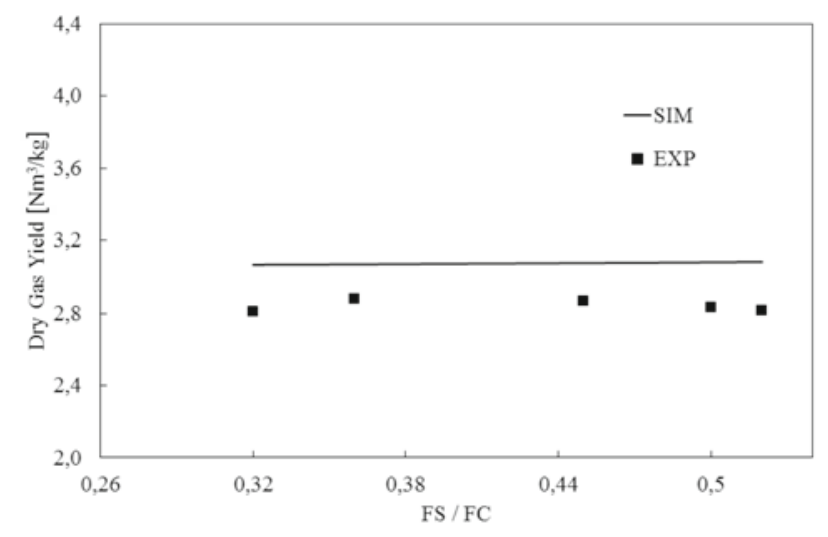

f)

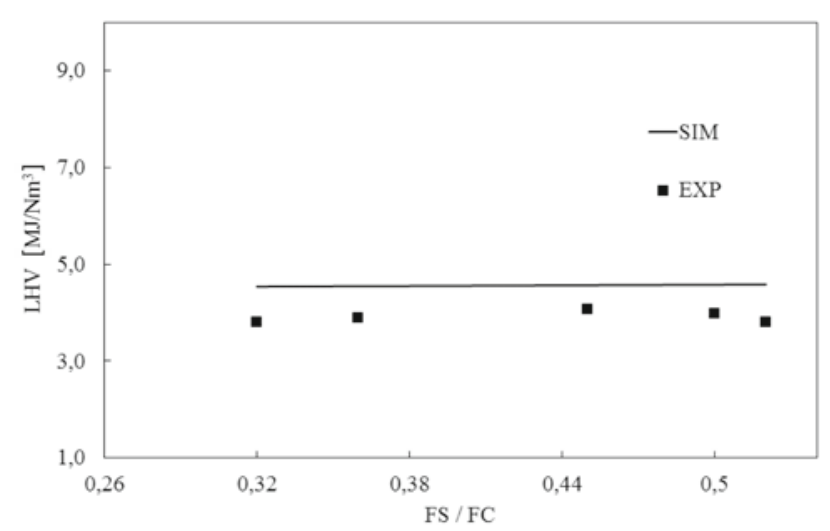

Figure 5. Effect of Steam to Coal Ratio on Gasification Parameters (Simulation vs. Experimental), Coal Feed Rate $=7.5 \mathrm{~kg} / \mathrm{h}$, $\mathrm{T}_{\mathrm{ga}}=700^{\circ} \mathrm{C}, \Phi=0.35$, (a) Gas Composition (except Nitrogen), (b) Nitrogen Composition, (c) Carbon Conversion Efficiency, (d) Dry Gas Yield, (e) Cold Gas Efficiency, (f) Gas LHV

It is clear from the Figure 9(a) that both $\mathrm{H}_{2}$ and $\mathrm{CO}$ increase with an increase in gasification temperature and this rate of increase becomes slow at higher values of $\mathrm{T}$. On the other hand $\mathrm{CO}_{2}$ shows a decreasing trend with an increase in gasification temperature. At $\mathrm{T}=850^{\circ} \mathrm{C}$, the $\mathrm{CO}$ concentration exceeds the $\mathrm{CO}_{2}$ concentration in the Syn. Gas with the gap further widened with high values of $\mathrm{T}$, so a high gasification temperature is preferred. The $\mathrm{N}_{2}$ and $\mathrm{CH}_{4}$ both decrease in the Syn. Gas with elevated gasification temperature which causes growth in the heating value of gas. Among Pakistan fields coal, $\mathrm{H}_{2}$ and $\mathrm{CO}$ concentrations are the maximum while $\mathrm{N}_{2}$ is the minimum for Jhimpir field. Rate of increase of $\mathrm{H}_{2}$ for Thar field coal is about double to that for Jhimpir coal field by elevated gasification temperature while Jhimpir field has higher rate of $\mathrm{CO}$ increase.

The overall gasification process along with carbon conversion is improved by increase in temperature. The rate of increase in carbon conversion efficiency becomes slow at higher gasification temperatures. Improved conversions are achieved for Thar coal but with lower rate of carbon conversion increase compared to the other fields. The trend for dry gas yield is increasing for elevated values of gasification temperature. This growth is due to decreased amount of $\mathrm{N}_{2}$ in the Syn. Gas. For Pakistan coal fields, Thar field produces less amount of Syn. Gas for any value of gasification temperature but has high rate of carbon conversion. 
a)

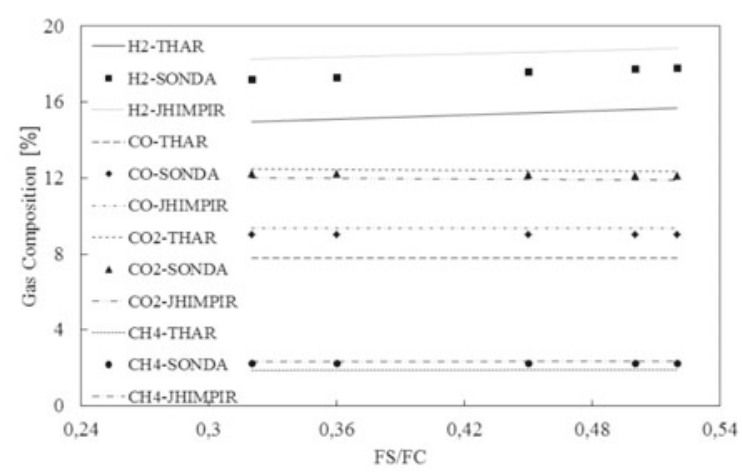

c)

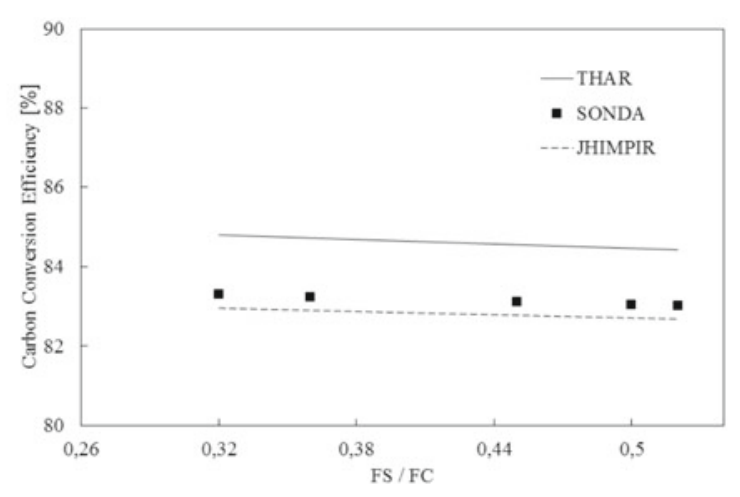

e)

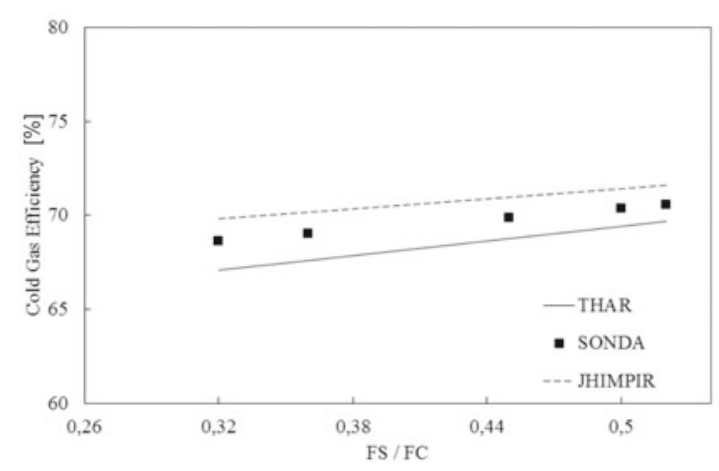

b)

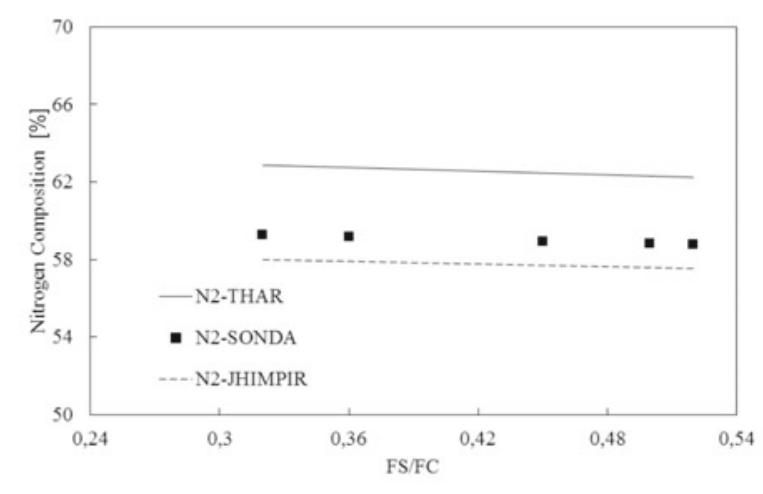

d)

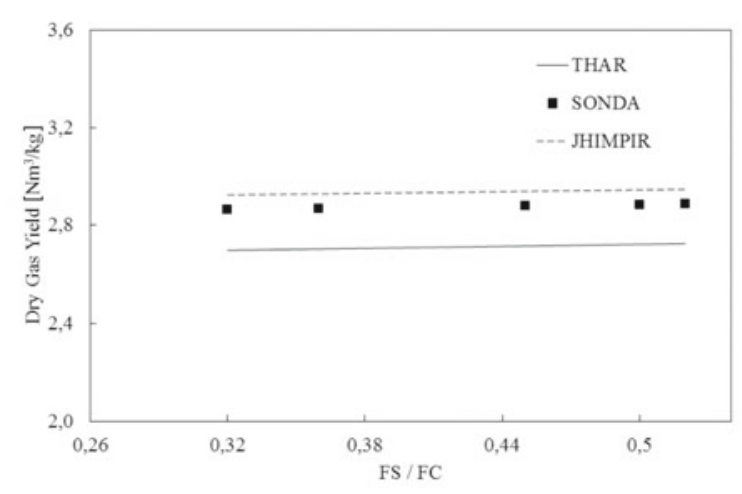

f)

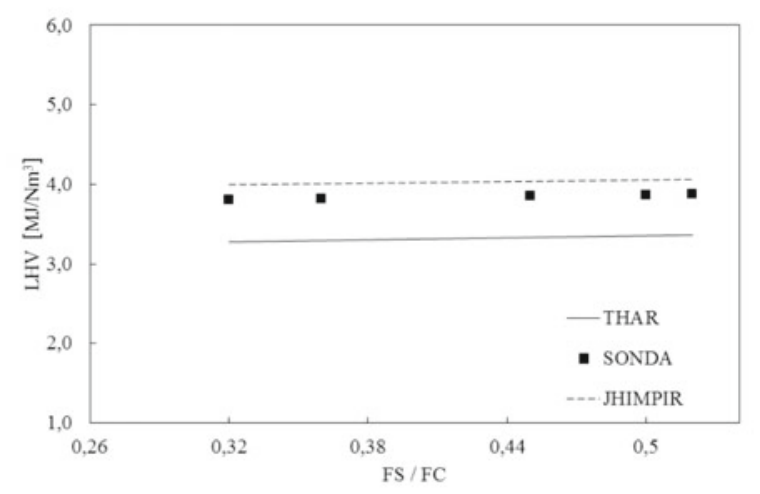

Figure 6. Effect of Steam to Coal Ratio on Gasification Parameters (Pakistan Coal Fields), Coal Feed Rate $=7.5 \mathrm{~kg} / \mathrm{h}, \mathrm{T}_{\mathrm{ga}}=700^{\circ} \mathrm{C}$, $\Phi=0.35$, (a) Gas Composition (except Nitrogen), (b) Nitrogen Composition, (c) Carbon Conversion Efficiency, (d) Dry Gas Yield, (e) Cold Gas Efficiency, (f) Gas LHV

For cold gas efficiency, the overall trend is increasing with an increase in gasification temperature because of an increase in yield and $\mathrm{H}_{2}$ and $\mathrm{CO}$ volume increase in the Syn. Gas. The rate of increase is fast for the lower gasification temperatures which becomes slow for higher gasification temperatures. For Pakistan coal fields, cold gas efficiency from Jhimpir coal field is the maximum than the other two fields but the trend of increase is lowest. The decreased amount of $\mathrm{CH}_{4}$ in the Syn. Gas has no impact on the LHV of the Syn. Gas. Heating value from Jhimpir coal field is the maximum amongst Pakistan coal fields but the increasing trend is less than the other fields.

\section{CONCLUSION}

A simulation model was developed using ASPEN PLUS for pressurized circulating fluidized bed gasification using different parameters and analyses of coal. The effect of various operating parameters was investigated on the composition of product gas, efficiency of carbon conversion, yield of gas, cold gas efficiency and LHV of gas. Various assumptions were incorporated to make the simulation feasible.

With the increase in amount of air, a decrease in Hydrogen, Carbon Monoxide, Carbon Dioxide and Methane is observed, which causes LHV and cold gas efficiency to decrease. While carbon conversion efficiency and dry gas yield tends to increase which is slow for carbon conversion. Same behavior is observed for Pakistan coal fields, but the Syn. Gas is rich in $\mathrm{CO}_{2}$ than $\mathrm{CO}$ with the maximum $\mathrm{H}_{2}$ and $\mathrm{CO}$ is in the Syn. Gas produced 
a)

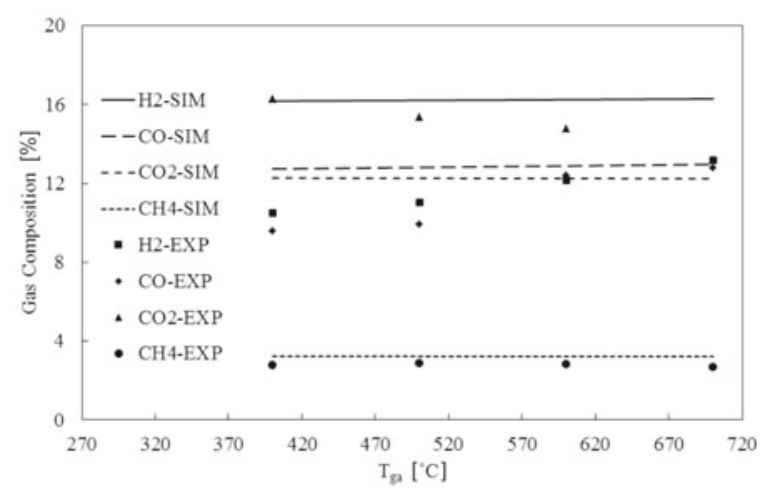

c)

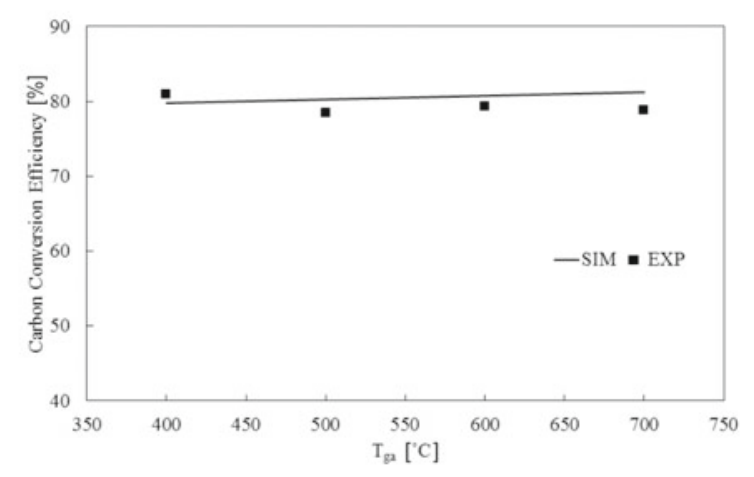

e)

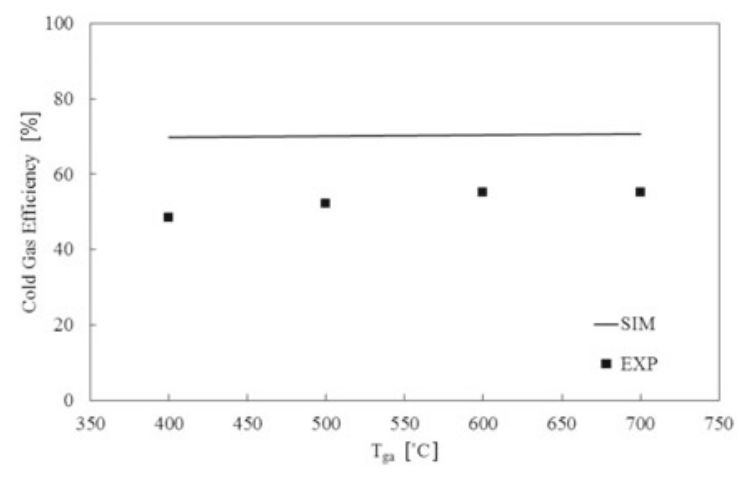

b)

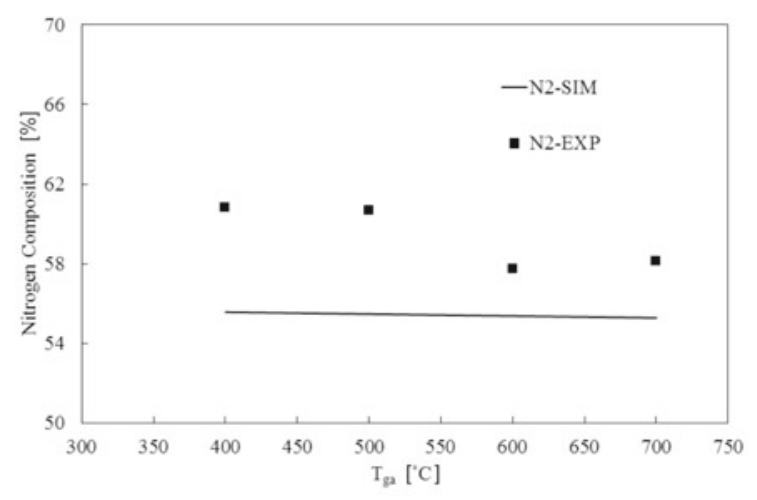

d)

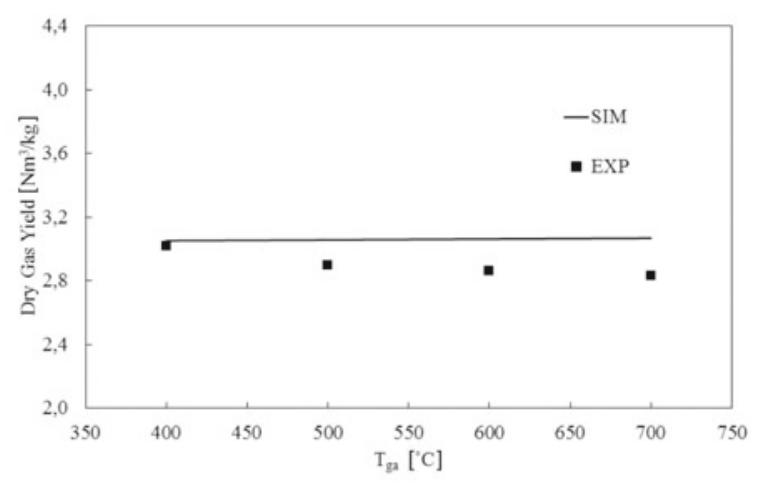

f)

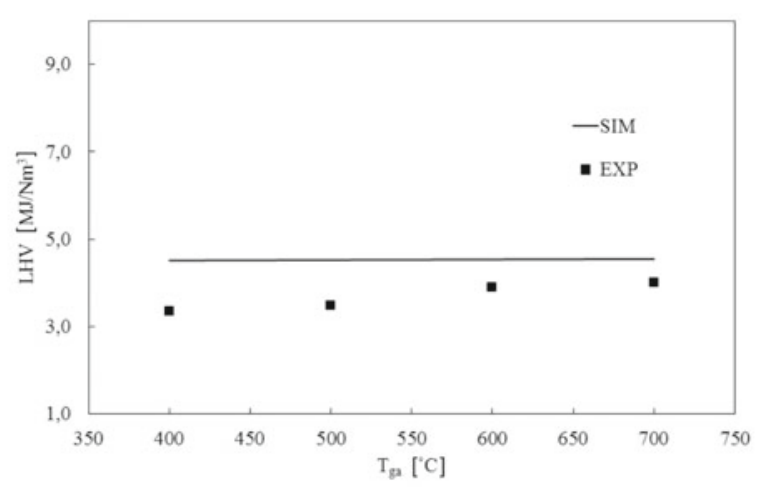

Figure 7. Effect of Gasification Agent Temperature on Gasification Parameters (Simulation vs. Experimental), Coal Feed Rate $=7.5 \mathrm{~kg} / \mathrm{h}, \mathrm{FS} / \mathrm{FC}=0.38, \Phi=0.35$, (a) Gas Composition (except Nitrogen), (b) Nitrogen Composition, (c) Carbon Conversion Efficiency, (d) Dry Gas Yield, (e) Cold Gas Efficiency, (f) Gas LHV

from Jhimpir field coal. A small value of $\Phi$ i.e. less air flow rate shows better results. Increasing the steam flow rate, favors $\mathrm{H}_{2}$ and $\mathrm{CO}$ concentration and the others components tend to decline. The other parameters like LHV, yield and cold gas efficiency have a small increasing trend. While the carbon conversion shows a slight falling trend. Same trends are observed for Pakistan coal fields, all parameters except composition have the minimum values for Jhimpir field. The $\mathrm{H}_{2}$ and $\mathrm{CO}$ amount is high for Syn. Gas produced from Jhimpir coal field. High steam flow rate favors the overall process.

Increment in gasifying agent temperature shows increasing behavior for composition, yield, efficiency of carbon conversion and LHV of Syn. Gas. The best results among Pakistan coal fields are observed for Jhimpir field which gives highest values for $\mathrm{H}_{2}$ and $\mathrm{CO}$ in Syn. Gas, yield and LHV etc. Gasification is favored with increased gasification agent temperature. Looking on the results for effect of gasification temperature, we realize that with increasing gasification temperature $\mathrm{H}_{2}$ and $\mathrm{CO}$ in Syn. Gas is maximized and $\mathrm{CO}_{2}, \mathrm{~N}_{2}$ and $\mathrm{CH}_{4}$ are minimized which results in an increase of carbon conversion, yield, efficiency of cold gas and gas LHV. The same behaviors are observed for Pakistan coal fields with the best values observed for Jhimpir field. A high gasification temperature is required to improve the gasification process ${ }^{\mathbf{1 3}}$.

\section{NOMENCLATURE}

A - Clusters decay constant in freeboard $\left[\mathrm{m}^{-1}\right]$

Ar - Archimedes number

$d_{p} \quad-$ particle diameter $[\mathrm{m}]$

$E \quad-$ Activation energy $[\mathrm{kcal} / \mathrm{mol}]$

$g \quad-$ Gravitational acceleration $\left[\mathrm{m} / \mathrm{s}^{2}\right]$

$k \quad-$ Rate constant $\left[\mathrm{s}^{-1} \mathrm{~atm}^{-1}\right]$

$P \quad$ - Pressure [MPa]

$R \quad-$ Universal gas constant $[\mathrm{kcal} / \mathrm{mol} . \mathrm{K}]$ 
a)

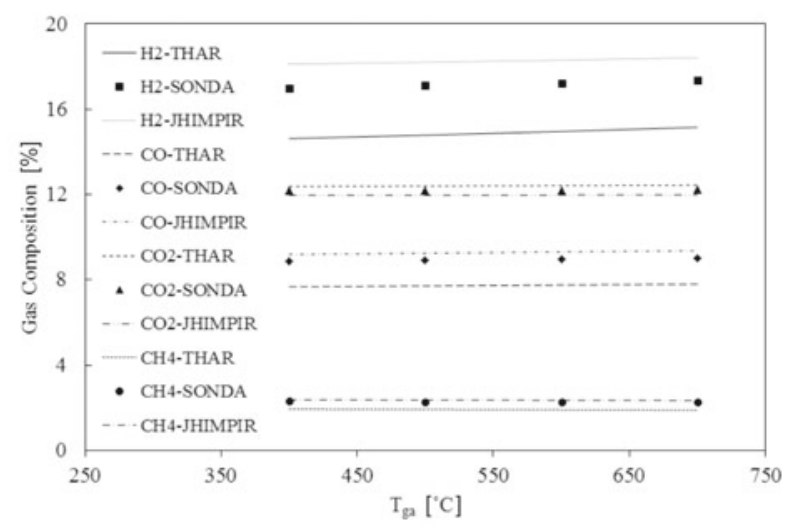

c)

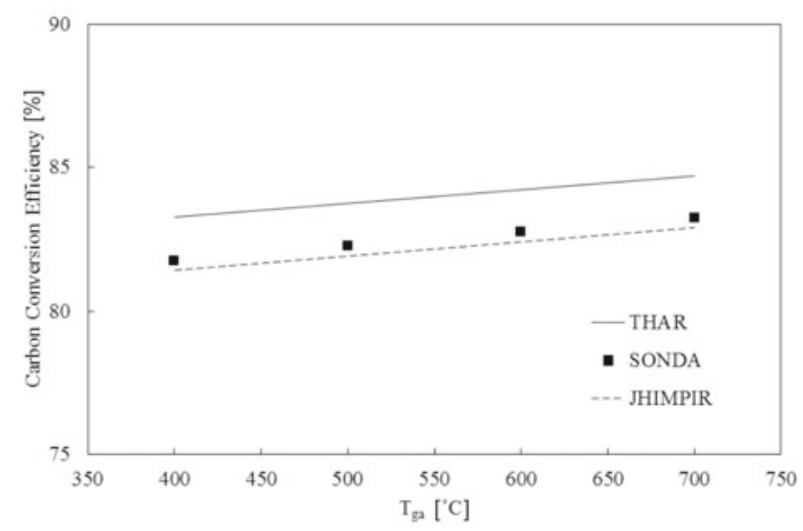

e)

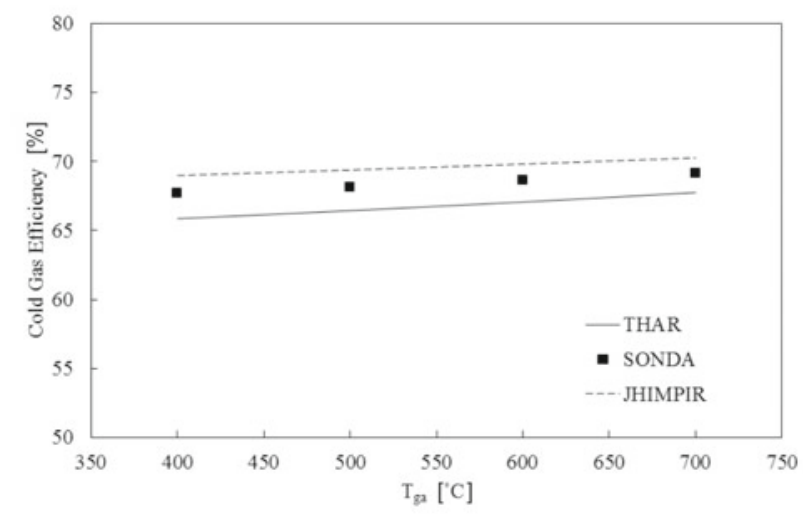

b)

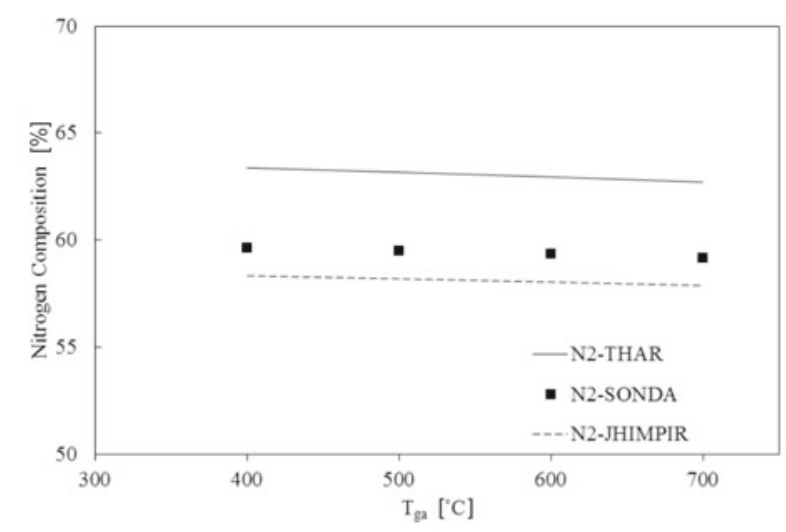

d)

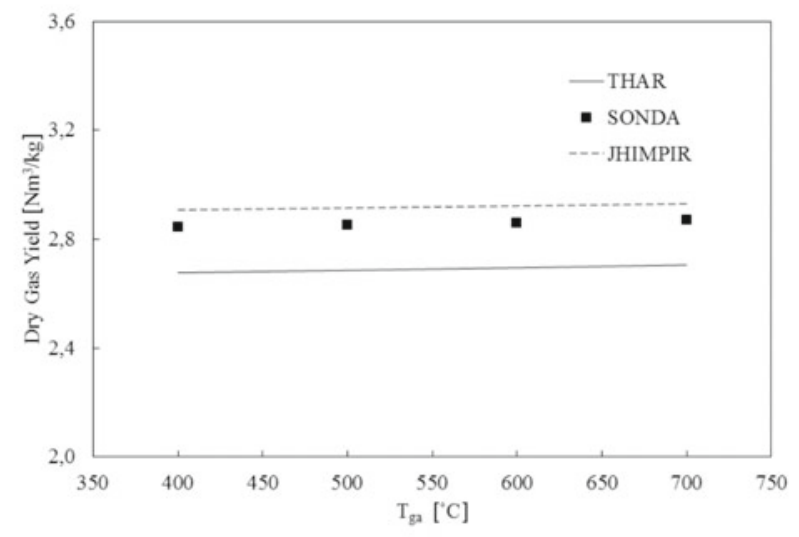

f)

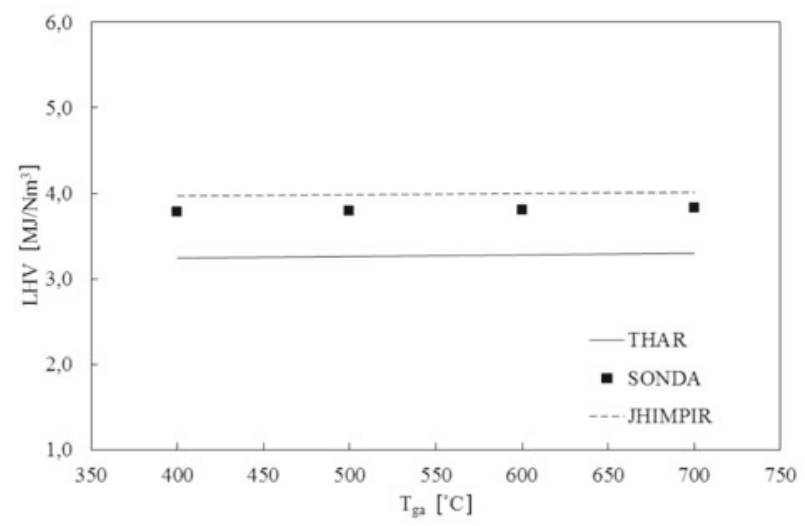

Figure 8. Effect of Gasification Agent Temperature on Gasification Parameters (Pakistan Coal Fields), Coal Feed Rate = 7.5 kg/h, $\mathrm{FS} / \mathrm{FC}=0.38, \Phi=0.35$, (a) Gas Composition (except Nitrogen), (b) Nitrogen Composition, (c) Carbon Conversion Efficiency, (d) Dry Gas Yield, (e) Cold Gas Efficiency, (f) Gas LHV

$u \quad$ - Superficial velocity $[\mathrm{m} / \mathrm{s}]$

$u_{m f} \quad-$ Minimum fluidization velocity $[\mathrm{m} / \mathrm{s}]$

$z$ - distance above the surface of the bed $[\mathrm{m}]$

$\alpha \quad-$ kinetics parameter

$\beta-$ kinetics parameter

$\varepsilon_{b} \quad$ - volume fraction of bed occupied by bubble

$\varepsilon_{f} \quad$ - average voidage of bed

$\varepsilon_{f b} \quad$ - average voidage of freeboard

$\varepsilon_{m f} \quad-$ voidage in emulsion at minimum fluidization

$\varrho_{g} \quad-$ density of gas $\left[\mathrm{kg} / \mathrm{m}^{3}\right]$

$\rho_{s} \quad-$ density of solid $\left[\mathrm{kg} / \mathrm{m}^{3}\right]$

$\mu \quad-$ viscosity $[\mathrm{kg} / \mathrm{m} . \mathrm{s}]$

$\eta_{\mathrm{c}} \quad$ - Carbon Conversion Efficiency

$\eta \quad$ - Cold Gas Efficiency

$\mathrm{H}_{\mathrm{g}} \quad-\mathrm{HHV}$ of Syn. Gas $\left[\mathrm{kJ} / \mathrm{Nm}^{3}\right]$

$\mathrm{H}_{\mathrm{c}}-\mathrm{HHV}$ of solid feed $[\mathrm{kJ} / \mathrm{kg}]$
Y - Dry Gas Yield $\left[\mathrm{Nm}^{3} / \mathrm{kg}\right]$

LHV - Lower Heating Value $\left[\mathrm{MJ} / \mathrm{Nm}^{3}\right]$

$\mathrm{Q}_{\mathrm{a}} \quad$ - Volumetric flow rate of Air $\left[\mathrm{Nm}^{3} / \mathrm{hr}\right]$

$\mathrm{W}_{\mathrm{c}} \quad$ - Coal mass flow rate $[\mathrm{kg} / \mathrm{hr}]$

\section{LITERATURE CITED}

1. Mirza, U.K., Ahmad, N. \& Majeed, T. (2008). An overview of biomass energy utilization in Pakistan. Renew. Sust. Energ. Rev. 12(7), 1988-1996. DOI: 10.1016/j.rser.2007.04.001.

2. Asif, M. (2009). Sustainable energy options for Pakistan. Renew. Sust. Energ. Rev. 13(4), 903-909. DOI: 10.1016/j. rser.2008.04.001.

3. Ju, F., Chen, H., Yang, H., Wang, X., Zhang, S. \& Liu, D. (2010). Experimental study of a commercial circulated fluidized bed coal gasifier. Fuel Process. Technol. 91(8), 818-822. DOI: 10.1016/j.fuproc.2009.07.013. 
a)

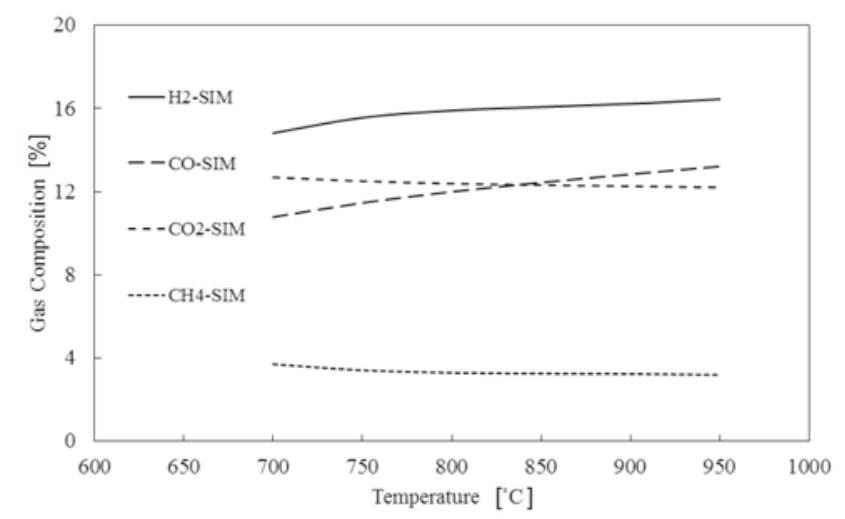

c)

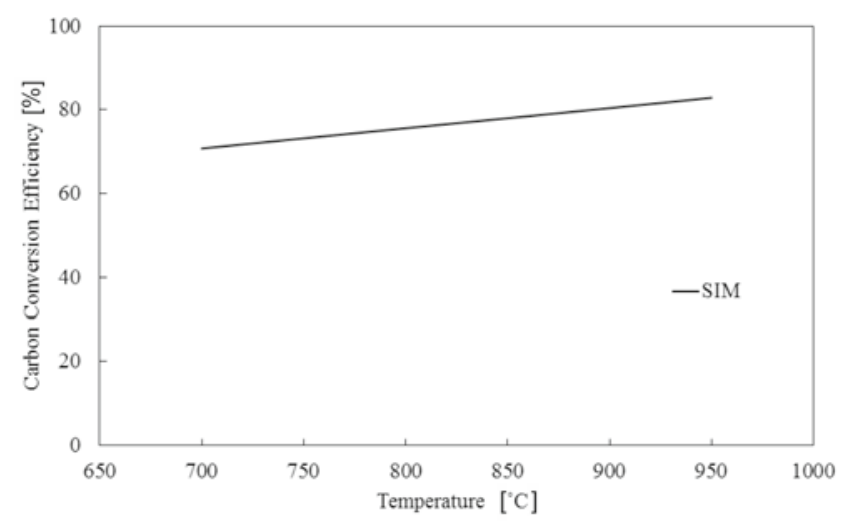

e)

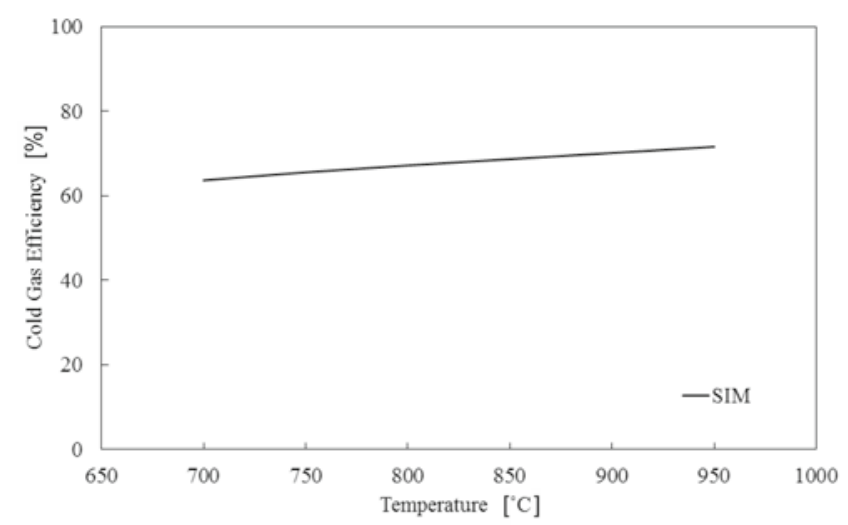

b)

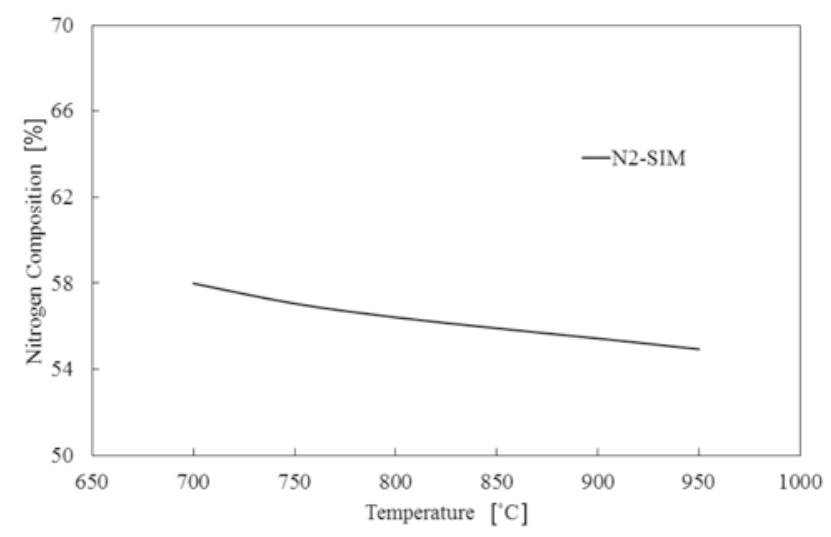

d)

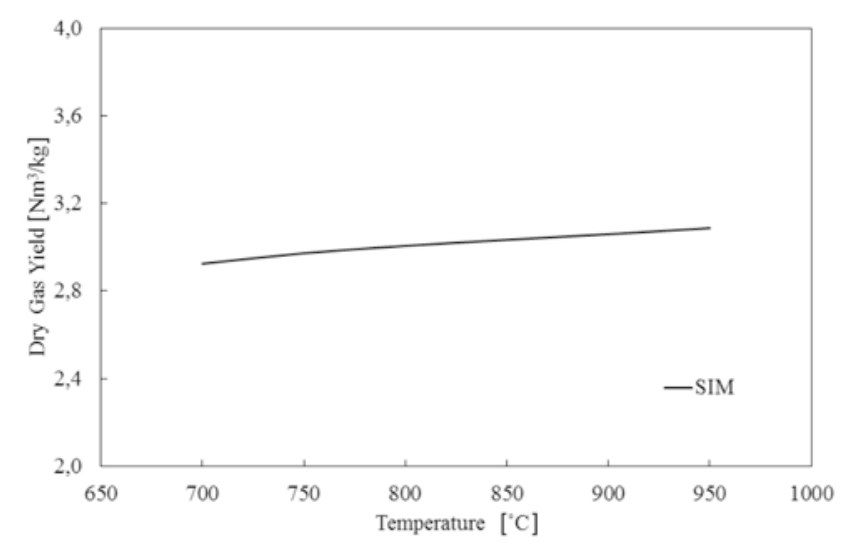

f)

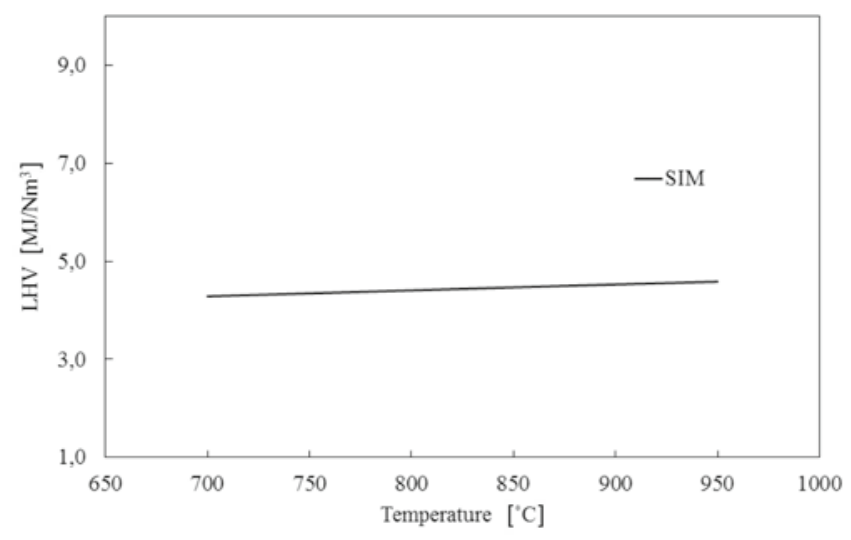

Figure 9. Effect of Gasification Temperature on Gasification Parameters (Simulation), Coal Feed Rate $=7.5 \mathrm{~kg} / \mathrm{h}, \mathrm{FS} / \mathrm{FC}=0.38$, $\Phi=0.35, \mathrm{~T}_{\mathrm{ga}}=700^{\circ} \mathrm{C}$, (a) Gas Composition (except Nitrogen), (b) Nitrogen Composition, (c) Carbon Conversion Efficiency, (d) Dry Gas Yield, (e) Cold Gas Efficiency, (f) Gas LHV

4. Bell, D.A., Towler, B.F. \& Fan, M. (2011). Coal gasification and its applications (1st ed). Oxford: William Andrew Publisher.

5. Nozawa, S. \& Matsushita, Y. (2013). Numerical investigation of the effect of the heterogeneous reaction model on the thermal behavior of pulverized coal combustion. Asia-Pac. J. Chem. Eng. 8, 292-300. DOI: 10.1002/apj.1694.

6. Wu, L., Qiao, Y. \& Yao, H. (2012). Experimental and numerical study of pulverized bituminous coal ignition characteristics in $\mathrm{O} 2 / \mathrm{N} 2$ and $\mathrm{O} 2 / \mathrm{CO} 2$ atmospheres. Asia-Pac. J. Chem. Eng. 7(S2), S195-S200. DOI: 10.1002/apj.590.

7. Basu, P. (2006). Combustion and gasification in fluidized beds. Boca Raton: CRC Press.

8. Ocampo, A., Arenas, E., Chejne, F., Espinel, J., Londono, C., Aguirre, J. \& Perez, J. (2003). An experimental study on gasification of Colombian coal in fluidised bed. Fuel 82(2), 161-164. DOI: 10.1016/S0016-2361(02)00253-3.

9. Nikoo, M.B. \& Mahinpey, N. (2008). Simulation of biomass gasification in fluidized bed reactor using ASPEN PLUS. Biomass Bioenerg. 32(12), 1245-1254. DOI: 10.1016/j. biombioe.2008.02.020.

10. Yan, H. \& Zhang, D. (1999). Modeling of a low temperature pyrolysis process using ASPEN PLUS. Dev. Chem. Eng. Mineral Process. 7(5-6), 577-591. DOI: 10.1002/apj.5500070511.

11. Lee, J.M., Kim, Y.J., Lee, W.J. \& Kim, S.D. (1998). Coal-gasification kinetics derived from pyrolysis in a fluidized-bed reactor. Energy 23(6), 475-488. DOI: 10.1016/S03605442(98)00011-5. 
a)

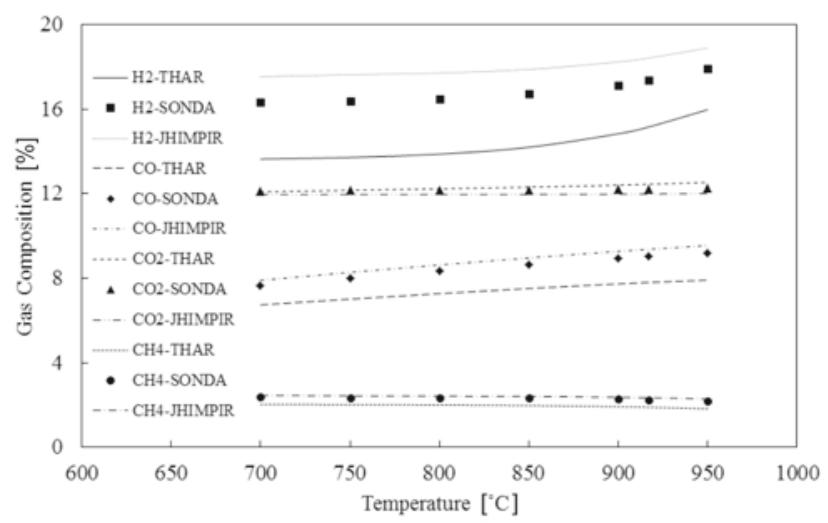

c)

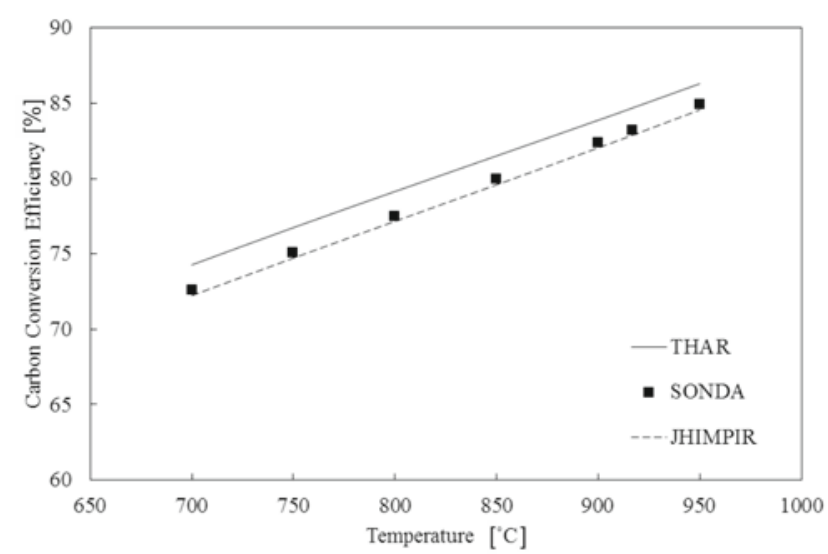

e)

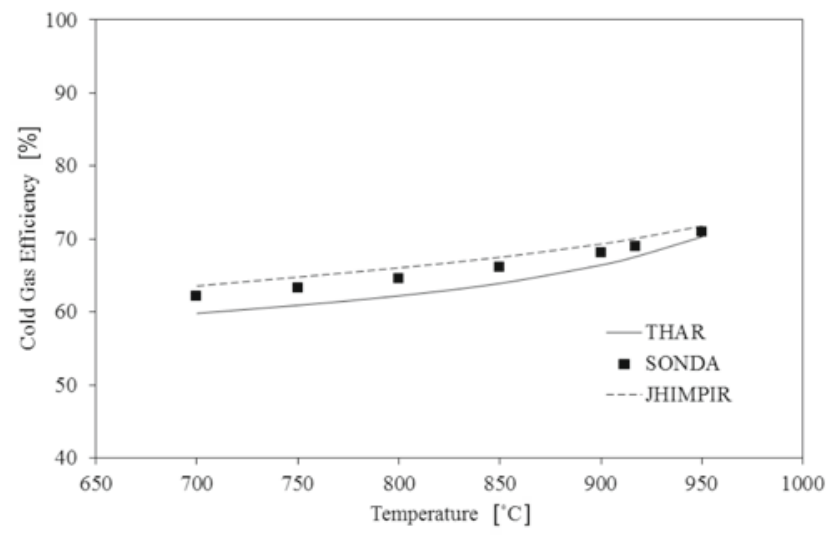

b)

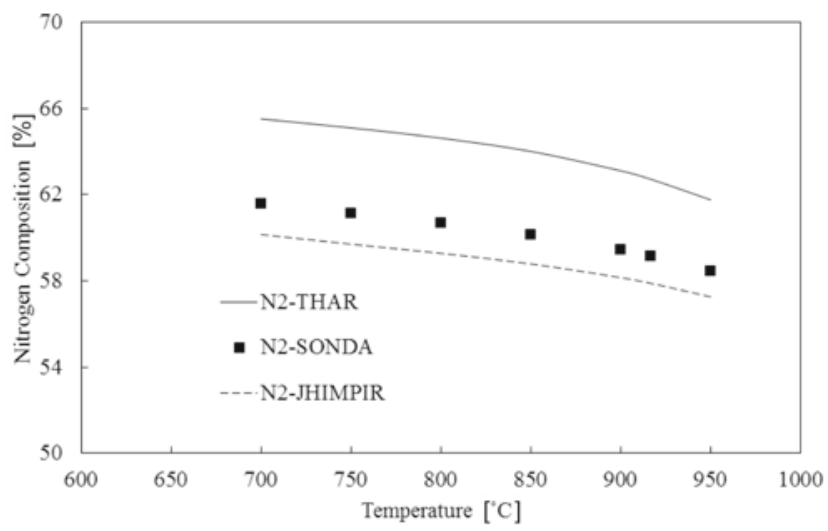

d)

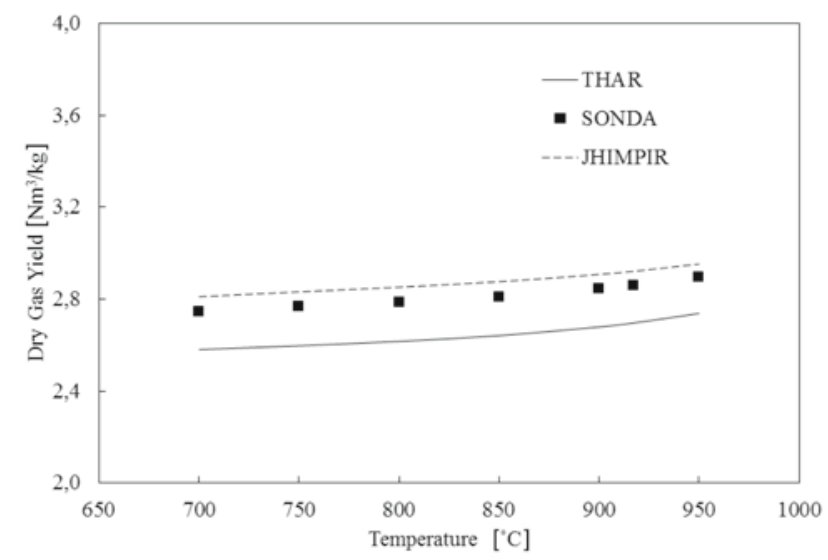

f)

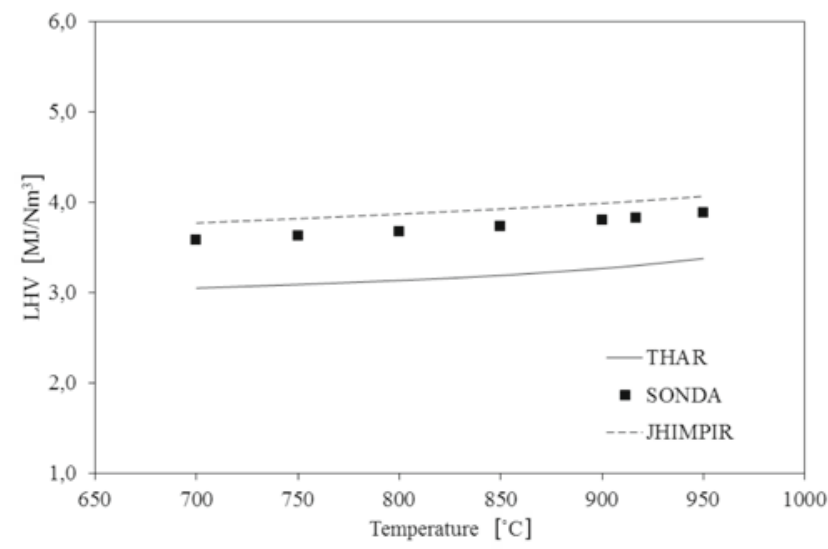

Figure 10. Effect of Gasification Temperature on Gasification Parameters (Pakistan Coal Fields), Coal Feed Rate $=7.5 \mathrm{~kg} / \mathrm{h}, \mathrm{FS} / \mathrm{FC}=0.38$, $\Phi=0.35, \mathrm{~T}_{\mathrm{ga}}=700^{\circ} \mathrm{C}$, (a) Gas Composition (except Nitrogen), (b) Nitrogen Composition, (c) Carbon Conversion Efficiency, (d) Dry Gas Yield, (e) Cold Gas Efficiency, (f) Gas LHV

12. Duan, F., Jin, B., Huang, Y., Li, B., Wu, Y. \& Zhang, M. (2010). Results of bituminous coal gasification upon exposure to a pressurized pilot-plant circulating fluidized-bed (CFB) reactor. Energ. Fuel. 24(5), 3150-3158. DOI: 10.1021/ef901596n.

13. Siddiqui, I. (2007) Environmental study of coal deposits of Sindh, with special reference to heavy and trace metal study in Thar, Sonda and Meting-Jhimpir coal field. PhD Thesis, University of Peshawar, Peshawar, Pakistan. 